\title{
O PAPEL DOS SEDIMENTOS EM SUSPENSÃO NO METABOLISMO DE RIOS DE MICRO E MESO-ESCALA NO ESTADO DE RONDÔNIA
}

\author{
Michelle Cristine Cogo
}

Dissertação apresentada à Escola Superior de Agricultura “Luiz de Queiroz”, Universidade de São Paulo, para obtenção do título de Mestre em Ecologia de Agroecossistemas.

P I R A C I C A B A

Estado de São Paulo - Brasil

Março - 2005 


\title{
O PAPEL DOS SEDIMENTOS EM SUSPENSÃO NO METABOLISMO DE RIOS DE MICRO E MESO-ESCALA NO ESTADO DE RONDÔNIA
}

\author{
Michelle Cristine Cogo \\ Bióloga
}

Orientador: Prof. Dr. ALEX VLADIMIR KRUSCHE

\begin{abstract}
Dissertação apresentada à Escola Superior de Agricultura "Luiz de Queiroz”, Universidade de São Paulo, para obtenção do título de Mestre em Ecologia de Agroecossistemas.
\end{abstract}

P I R A C I C A B A

Estado de São Paulo - Brasil

Março - 2005 
Dados Internacionais de Catalogação na Publicação (CIP) DIVISÃO DE BIBLIOTECA E DOCUMENTAÇÃO - ESALQ/USP

\section{Cogo, Michelle Cristine}

O papel dos sedimentos em suspensão no metabolismo de rios de micro e mesoescala no Estado de Rondônia / Michelle Cristine Cogo. - - Piracicaba, 2005.

61 p. : il.

Dissertação (mestrado) - - Escola Superior de Agricultura Luiz de Queiroz, 2005.

Bibliografia.

1. Bacia hidrográfica 2. Carbono orgânico 3. Cobertura do solo 4. Ecossistemas aquáticos 5. Ji-Paraná, Rio 6. Metabolismo 7. Sedimentos 8. Uso do solo I. Título

CDD 551.303

"Permitida a cópia total ou parcial deste documento, desde que citada a fonte - O autor" 
Ofereço

À Deus

Humildemente

À minha família

Em especial a minha mãe Magali

E meus irmãos Matheus e Mariana

dedico 


\section{AGRADECIMENTOS}

Ao Prof. Dr. Alex V. Krusche, pela orientação, revisões e os incentivos para o desenvolvimento desta dissertação;

Á Fundação de Amparo à Pesquisa do Estado de São Paulo (FAPESP) pela bolsa e reserva técnica concedida;

Ao Centro de Energia Nuclear na Agricultura (CENA), na pessoa do seu Diretor Prof. Dr. Reynaldo Luiz Victoria, por fornecer os meios necessários para a realização deste trabalho e pela confiança depositada à minha pessoa;

À Escola Superior de Agricultura “Luiz de Queiroz” (ESALQ - USP), através do Programa de Pós-Graduação Interunidades em Ecologia de Agroecossistemas pela oportunidade de aprendizado;

Ao projeto LBA (Large Scale Biosphere-Atmosphere) pela oportunidade de aprendizagem;

Ao pesquisador Dr. Anthony K. Aufdenkampe pela amizade e co-orientação durante todo o período;

A todos os pesquisadores do departamento que de forma direta ou indireta auxiliou na formulação desta dissertação;

À minha amiga, Alexandra Ayres Montebelo, por todo o apoio, principalmente em campo (sem ela seria inviável a realização deste trabalho) e, acima de tudo pelo coleguismo durante todo o tempo;

Aos meus amigos Nei, Marcos, Sérgio, Fátima, Vania, Adriana, Edgard, José Mauro, Rafael (Pira), Daniel, Cátia, Santiago, Lais, André, Letícia, Edmar, pelo bom convívio e acima de tudo por todos os momentos bons em que estivemos juntos; 
Aos demais amigos, funcionários e estagiários dos Laboratórios de Ecologia Isotópica e Geoprocessamento, pela amizade;

Aos funcionários da Biblioteca Central, especialmente à Eliana e Silvia, pela paciência nas correções deste documento;

A todos aqueles que direta ou indiretamente contribuíram para a execução deste trabalho;

E finalmente, a minha mais do que amada MÃE (Magali), que esteve presente em todos os momentos, me apoiando e me dando forças para que a finalização deste trabalho fosse possível. 


\section{SUMÁRIO}

Página

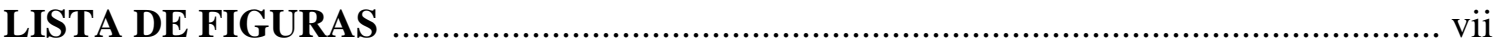

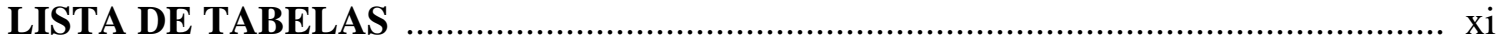

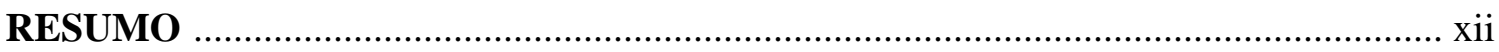

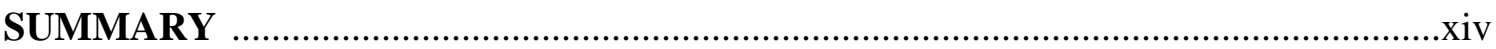

1 INTRODUÇÃ

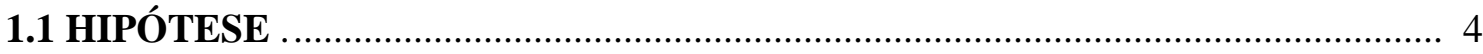

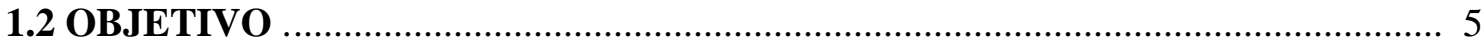

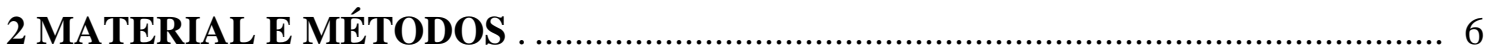

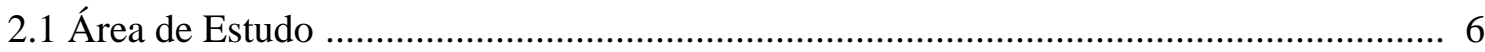

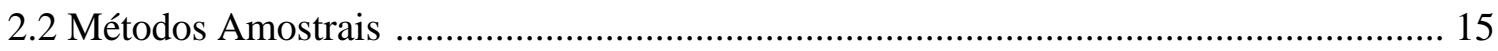

2.3 Experimentos de enriquecimento com sedimentos em suspensão ................................. 16

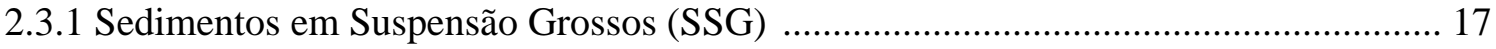

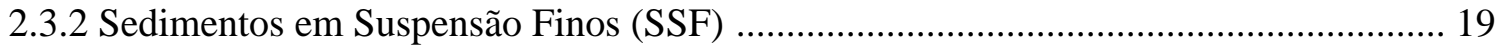

2.3.3 Incubações no escuro para determinar o consumo de oxigênio .................................. 21

2.3.4 Determinação das taxas respiratórias ....................................................................... 23

2.4 Determinação das concentrações de carbono orgânico dissolvido (COD) ..................... 23

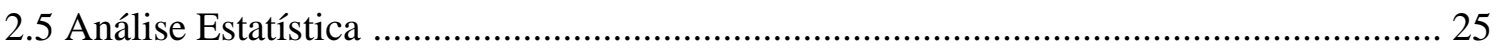

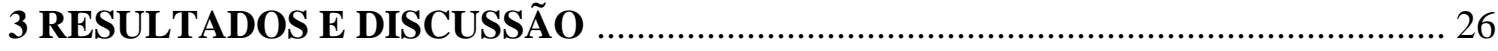

3.1 Variações Sazonais e Espaciais das concentrações de carbono orgânico dissolvido

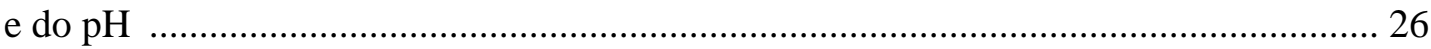

3.2 Experimentos de aumento das concentrações de Sedimentos em Suspensão Finos ....... 29

3.3 Experimentos com adição de concentrados de Sedimento em Suspensão Grosso ......... 44

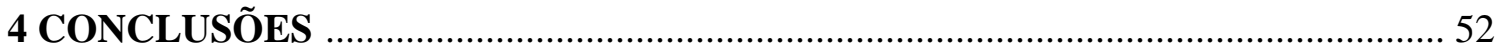

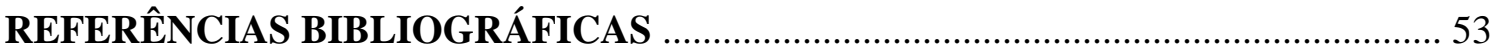




\section{LISTA DE FIGURAS}

Página

1 Identificação dos pontos amostrados e delimitação da bacia do rio Ji-Paraná. 1 Igarapé Boa Vista - floresta (BVF), 2 - Igarapé Boa Vista - pastagem (BVP), 3 Rio Urupá (URU), 4 - Rio Comemoração (COM) e, 5 - Rio Ji-Paraná (JIP)

2 Mapa de uso da terra na bacia do rio Ji-Paraná, conforme observado em imagens de julho e setembro de 1999 obtidas pelo satélite Landsat-7, ETM+. Dados obtidos do Tropical Rainforest West Inventory

3 Mapa de unidades de solos da bacia do rio Ji-Paraná (EMBRAPA, 1983), modificado para o novo sistema de classificação de solos (EMBRAPA, 1999)......

4 Mapa de saturação de bases, criado a partir dos dados do SIGTERON. Foram utilizados os dados de 1041 perfis de solo, a uma profundidade de $20 \mathrm{~cm}$. Para obtenção de uma superfície contínua foi aplicada análise geoestatística

5 Média das descargas diárias do rio Ji-Paraná, na cidade de Ji-Paraná (1978 a 2003), Fonte: Agência Nacional de Águas - ANA. As setas indicam os períodos em que foram efetuadas as amostragens

6 Ilustração do esquema utilizado em campo para as amostragens das águas dos rios 
8 Ilustração dos experimentos enriquecidos com Sedimentos em Suspensão Finos .... 19

9 Garrafas utilizadas nas incubações 22

10 Organograma das amostras retiradas para determinação das concentrações de Oxigênio Dissolvido nos experimentos de adição de sedimentos $\mathrm{N}_{\mathrm{x}}=$ Controle, $F_{\mathrm{x}}=$ Amostras pré-concentradas com sedimentos em suspensão finos e $G_{\mathrm{x}}=$ Amostras que receberam sedimentos em suspensão grossos

11 Equipamentos utilizados em laboratório. A - Analisador de Carbono Shimadzu modelo TOC 5000A, B - Auto-Titulador da marca Mettler Toledo, modelo DL77

12 Concentrações médias de carbono orgânico dissolvido nas águas dos rios amostrados neste estudo, em distintas épocas da hidrógrafa. Valores em $\mu \mathrm{M} / \mathrm{L}$..... 27

13 Valores de $\mathrm{pH}$ das águas dos rios estudados, nos diferentes períodos amostrados.... 28

14 Concentrações de carbono orgânico dissolvido (COD), nas amostras Controle (C) e enriquecidas com Sedimentos em Suspensão Finos (F), no rio Comemoração

15 Concentrações de carbono orgânico dissolvido (COD), nas amostras Controle (C) e enriquecidas com Sedimentos em Suspensão Finos (F), no rio Urupá 31

16 Concentrações de carbono orgânico dissolvido (COD), nas amostras Controle (C) e enriquecidas com Sedimentos em Suspensão Finos (F), no rio Ji-Paraná 
17 Concentrações de carbono orgânico dissolvido (COD), nas amostras Controle (C) e enriquecidas com Sedimentos em Suspensão Finos (F), no Igarapé Boa Vista, no trecho da Pastagem

18 Concentrações de carbono orgânico dissolvido (COD), nas amostras Controle (C) e enriquecidas com Sedimentos em Suspensão Finos (F), no Igarapé Boa Vista, no trecho da Floresta

19 Variações das taxas respiratórias no rio Comemoração, após 24 e 48 horas de incubação dos experimentos Controle (C) e enriquecidos com Sedimentos em Suspensão Finos (F). Valores em $\mu \mathrm{M} \cdot \mathrm{h}^{-1}$

20 Variações das taxas respiratórias no rio Urupá, após 24 e 48 horas de incubação dos experimentos Controle (C) e enriquecidos com Sedimentos em Suspensão Finos (F). Valores em $\mu \mathrm{M} . \mathrm{h}^{-1}$

21 Variações das taxas respiratórias no rio Ji-Paraná, após 24 e 48 horas de incubação dos experimentos Controle (C) e enriquecidos com Sedimentos em Suspensão Finos (F). Valores em $\mu \mathrm{M} \cdot \mathrm{h}^{-1}$

22 Variações das taxas respiratórias no Igarapé Boa Vista Pastagem, após 24 e 48 horas de incubação dos experimentos Controle (C) e enriquecidos com Sedimento em Suspensão Fino (F). Valores em $\mu \mathrm{M} \cdot \mathrm{h}^{-1}$

23 Variações das taxas respiratórias no Igarapé Boa Vista Floresta, após 24 e 48 horas de incubação dos experimentos Controle (C) e enriquecidos com Sedimento em Suspensão Fino (F). Valores em $\mu \mathrm{M} \cdot \mathrm{h}^{-1}$ 
24 Variação das taxas respiratórias no rio Comemoração, após 24 e 48 horas de incubação, nas amostras Controle (C) e enriquecidas com Sedimentos em Suspensão Grossos (G). Valores em $\mu \mathrm{M} \cdot \mathrm{h}^{-1}$

25 Variação das taxas respiratórias no rio Urupá, após 24 e 48 horas de incubação, nas amostras Controle (C) e enriquecidas com Sedimentos em Suspensão Grossos (G). Valores em $\mu \mathrm{M} \cdot \mathrm{h}^{-1}$

26 Variação das taxas respiratórias no rio Ji-Paraná, após 24 e 48 horas de incubação, nas amostras Controle (C) e enriquecidas com Sedimentos em Suspensão Grossos (G). Valores em $\mu \mathrm{M} \cdot \mathrm{h}^{-1}$

27 Variação das taxas respiratórias no setor da pastagem do Igarapé Boa Vista, após 24 e 48 horas de incubação, nas amostras Controle (C) e enriquecidas com Sedimentos em Suspensão Grossos (G). Valores em $\mu \mathrm{M} \cdot \mathrm{h}^{-1}$

28 Variação das taxas respiratórias no setor da floresta do Igarapé Boa Vista, após 24 e 48 horas de incubação, nas amostras Controle (C) e enriquecidas com Sedimentos em Suspensão Grossos (G). Valores em $\mu M^{-1}{ }^{-1}$ 


\section{LISTA DE TABELAS}

\section{Página}

1 Identificação dos graus de impacto antropogênico das bacias dos rios amostrados ... 15

2 Massas de sedimentos em suspensão grossos (SSG, em mg) adicionados às amostras de águas de rios de Rondônia................................................................... 18

3 Concentrações dos sedimentos em suspensão finos (SSF, em mg/L), nas amostras de água de rios, antes e após o procedimento de pré-concentração por ultrafiltração 


\title{
O PAPEL DOS SEDIMENTOS EM SUSPENSÃO NO METABOLISMO DE RIOS DE MICRO E MESO-ESCALA NO ESTADO DE RONDÔNIA
}

\author{
Autor (a): MICHELLE CRISTINE COGO \\ Orientador: Prof. Dr. ALEX VLADIMIR KRUSCHE
}

\section{RESUMO}

As águas superficiais da Amazônia, que englobam, dentre outros, rios das mais variadas ordens, desde pequenos igarapés, até o rio Amazonas, um dos maiores do mundo, são um componente importante do funcionamento deste ecossistema de escala continental. Um paradigma acerca dos sistemas fluviais é que estes integram os processos que ocorrem em suas bacias de drenagem e, portanto, alterações na cobertura vegetal e nos usos da terra, podem interferir diretamente nos parâmetros físicos e químicos dos compartimentos aquáticos. Algumas áreas da Amazônia, como o estado de Rondônia, por exemplo, têm sofrido alterações substanciais nas suas bacias de drenagem e as conseqüências destas nos sistemas fluviais ainda são pouco compreendidas. Sabe-se que a conversão de florestas em pastagens, o tipo de alteração mais comum nos ecossistema de Rondônia, resulta na compactação dos solos e no aumento da erosão. Ao mesmo tempo, diversos estudos têm demonstrado que os sedimentos em suspensão, carreados nos rios, podem ser importantes fontes de carbono e outros nutrientes limitantes para o metabolismo aquático. Com base nestas premissas, este estudo visou avaliar a importância dos sedimentos em suspensão grossos (maiores que $63 \mu \mathrm{m}$ ) e finos (menores que $63 \mu \mathrm{m}$ e maiores $0,1 \mu \mathrm{m}$ ) no metabolismo de alguns rios de Rondônia, sob diversas coberturas e usos da terra. Para tal, as concentrações destes sedimentos foram 
artificialmente aumentadas em amostras incubadas no escuro, nas quais os consumos de oxigênio indicaram as taxas respiratórias. No caso dos sedimentos em suspensão finos, observaram-se aumentos nas taxas respiratórias em praticamente todos os casos nos quais suas concentrações foram aumentadas. Os sedimentos em suspensão grossos, por outro lado, somente favorecem aumentos nas taxas respiratórias nos períodos de maiores precipitações. Estes resultados relacionam-se com a composição dos sedimentos. Sedimentos em suspensão finos, por sua maior capacidade de adsorver substâncias orgânicas e nutrientes, constituem uma fonte permanente de substrato para o metabolismo aquático. Sedimentos em suspensão grossos, por outro lado, somente carreiam fração substancial de material orgânico durante o período de maiores precipitações, quando os solos são "lavados” pelas enxurradas. Apesar destas diferenças no papel relativo destas duas frações do material particulado no metabolismo destes rios, fica evidente que o aumento da erosão pode acarretar mudanças significativas no metabolismo dos sistemas fluviais da Amazônia. 


\title{
THE ROLE OF SUSPENDED SEDIMENTS IN THE METABOLISM OF MICRO AND MESO SCALE RIVERS OF RONDONIA, BRASIL
}

\author{
Author (a): MICHELLE CRISTINE COGO \\ Adviser: Prof. Dr. ALEX VLADIMIR KRUSCHE
}

\section{SUMMARY}

Amazonian surface waters, encompassing rivers of distinct orders, from small streams to one of the largest of the world, the Amazon, are important components of the functioning of this continental-scale ecosystem. A paradigm about fluvial systems is that they integrate the processes that occur at their watersheds and, therefore, changes in land use/cover may directly interfere on physical and chemical parameters of the aquatic compartments. In some areas of the Amazon, such as in the state of Rondonia, for example, the landscape has been significantly altered, and the consequences of these changes are still poorly understood. It is well know that the conversion of forests into pastures, a common type of land use change in Rondonia, can cause the compactation of soils and increased erosion rates. At the same time, several studies have demonstrated that suspended sediments can be important sources of carbon and other nutrients to river metabolism. Based on those assumptions, this study aimed the evaluation of the importance of coarse (larger than $63 \mu \mathrm{m}$ ) and fine (smaller than $63 \mu \mathrm{m}$ and larger than $0,1 \mu \mathrm{m}$ ) suspended sediments on the metabolism of some rivers of Rondonia. This assessment was made through incubations in the dark of samples enriched in sediments, in which the consumption of oxygen indicated respiration rates. In the case of fine suspended sediments, most incubated samples showed increased respiration rates as a 
result of the concentration of these particles. Coarse suspended sediments, on another side, only favor the increase in respiration rates during the high water period. These results are related to the composition of these sediments. Fine suspended sediments constitute a constant substract for the aquatic metabolism, as a result of their larger surface area and capacity for absorving organic substances and nutrients. Coarse sediments, however, only favor respiration during the high water period, when overland flow carries organic debris from land into the water systems. Although these two fractions of suspended sediments have different relative roles in the metabolism of rivers, it becomes evident from this data that increasing the erosion in the Amazon may affect significantly the metabolism of fluvial systems in this region. 


\section{INTRODUÇÃO}

A Amazônia é um dos mais importantes ecossistemas do planeta, devido a extensão de suas florestas, à biodiversidade que estas apresentam e as elevadas taxas em que estão sendo destruídas. Segundo dados do Ministério do Meio Ambiente (MMA, 2004), somente entre os meses de Agosto de 2002 e 2003, $23.750 \mathrm{~km}^{2}$ foram desmatados na Amazônia brasileira. As conseqüências deste processo na estrutura e funcionamento dos ecossistemas da região ainda exigem estudos mais detalhados (Victoria, 2004; Davidson et al., 2004).

Nos estados de Rondônia, Maranhão, Pará e Mato Grosso encontram-se mais de 85\% das áreas desmatadas na Amazônia (Hanada, 2004). Vários fatores levaram a estas elevadas taxas de desmatamento, tais como os incentivos fiscais, e criação de créditos rurais. Contribuíram também investimentos em rodovias, associadas a grandes projetos de colonização, como a construção da BR-364 e a Transamazônica. No estado de Rondônia, o principal mecanismo utilizado nestas alterações tem sido a conversão de florestas em pastagens, acarretando em uma área desmatada em torno de $3.463 \mathrm{~km}^{2}$ somente no ano de 2003 (MMA, 2004).

Uma outra característica peculiar da região Amazônica é a abundância de seus recursos hídricos, cuja extensa rede de drenagem culmina em um dos maiores rios do mundo. Segundo Cleto Filho (2003), estima-se que cada quilômetro quadrado da região central da Amazônia contenha aproximadamente de 2 a $4 \mathrm{~km}$ de pequenos rios, denominados regionalmente como "igarapés". O estado de Rondônia apresenta também uma ampla rede de drenagem, da qual fazem parte os rios Madeira, Ji-Paraná, Mamoré, Guaporé e Jamari. 
Diversos estudos descrevem a hidrologia e a biogeoquímica do rio Amazonas e seus principais tributários (Gibbs, 1967; Stallard \& Edmond, 1983, 1987; Meade et al., 1985; Forsberg et al., 1988; Richey \& Victoria, 1993). Nesta escala (macro-escala), os efeitos do desmatamento na região ainda parecem ser indetectáveis, tendo em vista que predominam as áreas de floresta nativa nesta bacia de drenagem de dimensões continentais. Porém, estudo recente na fazenda Nova Vida, no estado de Rondônia, demonstra alterações drásticas nos ciclos de nutrientes em rios de primeira e segunda ordem, mas que deixam de ser perceptíveis a medida em que a ordem dos mesmos aumenta (Thomas et al., 2004).

Outros estudos realizados no hemisfério Norte por Likens et al. (1970), Vitousek (1979) e Swank \& Crossley (1988) evidenciam que a remoção de florestas nativas pode acarretar em aumentos da erosão e temperatura do solo, em modificações no balanço hídrico (vazão e precipitação), disponibilidade de nutrientes no solo, bem como alterar o transporte de sedimentos e matéria orgânica para os ambientes aquáticos (Hunsaker \& Levine, 1995; Sharpley et al., 1995; Meyer et al., 1988; Melack, 1995). Portanto, alterações na parte terrestre das bacias de drenagem podem alterar significativamente a dinâmica dos seus ambientes aquáticos. Tais mudanças podem ser mais evidentes nos rios de pequena ordem, já que constituem o elo mais direto entre os ambientes terrestre e aquático.

No estado de Rondônia, Leite (2004), em estudo realizado na bacia do rio JiParaná, considerado um rio de meso-escala (bacia de drenagem de aproximadamente $75.000 \mathrm{~km}^{2}$ ), observou que as maiores concentrações dos nutrientes C, N e P ocorrem nos rios localizados nas regiões mais alteradas pela presença humana, indicando que tais mudanças no uso da terra talvez já estejam se refletindo na biogeoquímica destas águas. Neill et al. (2001), em estudos realizados em igarapés da fazenda Nova Vida (RO), observaram que alterações no uso e cobertura do solo provocaram mudanças nas concentrações de nutrientes, aumento na temperatura da água do igarapé e na quantidade de energia solar que atinge o canal, afetando a disponibilidade e a concentração de materiais particulados e dissolvidos. 
A quantidade de energia solar que chega até o canal afeta diretamente os organismos que compõe a comunidade aquática, uma vez que a luz é principal fonte de energia para o processo de fotossíntese (Wetzel, 1995). Na fazenda Nova Vida, a substituição das florestas por pastagens alterou significativamente a dinâmica de igarapés de primeira e segunda ordem (Thomas et al., 2004; Krusche, com. pess.). Com a retirada da floresta, a produtividade primária deixa de ser limitada pela luz, ocorrendo intenso desenvolvimento de gramíneas nativas nas margens e dentro dos canais dos igarapés da pastagem. Como resultado, os processos respiratórios também se intensificam e as condições aeróbias, observadas na floresta, passam a ser quase anoxia na pastagem.

Em sistemas aquáticos, os processos respiratórios podem ser controlados por fontes de energia autóctones ou alóctones, sendo as primeiras mais importantes nos sistemas lênticos e as segundas nos sistemas lóticos (Margalef, 1990). Em rios, grande parte do carbono necessário para o metabolismo provém de fontes alóctones, como sedimentos, folhas e outros resíduos vegetais, produzidos no ambiente terrestre, e transportados pelo escoamento superficial durante os períodos mais chuvosos (Ittekot \& Laane, 1991). Outra fração significativa de carbono que adentra os rios se encontra na forma dissolvida, e provém da lixiviação da liteira e dos solos, pela água que infiltra no terreno e atinge os canais através da drenagem sub-superficial ou subterrânea (Aitkenhead-Peterson et al., 2003). As quantidades e a importância relativa de cada uma destas fontes é função de diversos fatores, como cobertura vegetal, relevo, tipos de solos, clima (Ludwig, 1996).

Alguns estudos feitos na Amazônia têm demonstrado que uma das conseqüências da substituição de florestas por pastagens é o aumento do potencial de ocorrência de transporte lateral ao longo dos canais dos rios (Kauffman et al., 1998; McClain \& Elsenbeer, 2001). Com aumento da erosão, pode-se antecipar também um aporte maior de nutrientes para estes sistemas fluviais, uma vez que os sedimentos transportados pelo escoamento superficial são compostos por frações orgânicas e inorgânicas, resultantes de processos físicos, químicos e biológicos que ocorrem em suas bacias de drenagem 
(Thomaz, Pereira \& Pagioro, 2001), e constituídos por minerais de areia, silte e argila, misturados a matéria orgânica e nutrientes.

Portanto, pode-se pressupor que um aumento nas concentrações de sedimentos em suspensão nos rios, resultante da substituição das florestas por pastagens e aumento da erosão, possa vir a afetar também o metabolismo destes sistemas, com aumento das taxas respiratórias devido a estas fontes extras de carbono e outros nutrientes.

Neste sentido, o presente estudo visa determinar, experimentalmente, qual a resposta das comunidades aquáticas à adição de sedimentos grossos (maiores que 63 $\mu \mathrm{m}$ ) e finos (menores que $63 \mu \mathrm{m}$ e maiores que $0,1 \mu \mathrm{m}$ ). Para tal, foram utilizadas amostras de águas de rios do estado de Rondônia, onde o desmatamento é intenso. As concentrações de sedimentos nestas amostras foram artificialmente elevadas, para serem então incubadas no escuro por 24 e 48 hs. Finalmente, relacionaram-se tais incrementos com as variações observadas nas taxas respiratórias, entendidas aqui como um indicador do metabolismo destes sistemas.

\subsection{HIPÓTESE}

Como os sedimentos em suspensão em rios são constituídos de uma mistura de minerais, compostos orgânicos e outros nutrientes, podem ser um importante fator controlador do metabolismo dos mesmos e, portanto, alterações nas bacias de drenagem

que modifiquem as taxas de transporte destes sedimentos, do ambiente terrestre para o aquático, podem alterar a dinâmica dos sistemas fluviais na Amazônia. 


\subsection{OBJETIVOS}

- Quantificar as taxas respiratórias em rios de micro e meso-escala do estado de Rondônia, sob distintos usos e cobertura da terra,

- Quantificar os efeitos da variação das concentrações de sedimentos finos e grossos nas taxas respiratórias destes rios, compreendidas aqui como uma aproximação do metabolismo destes sistemas. 


\section{MATERIAL E MÉTODOS}

\section{1 Área de Estudo}

Os rios amostrados neste estudo estão localizados na bacia do rio Ji-Paraná, cujo curso se estende do Sudeste ao Norte do estado de Rondônia (Figura 1). Com uma área de drenagem de $75.400 \mathrm{~km}^{2}$, apresenta setores relativamente bem preservados, mais ao Sul e ao Norte, e uma região central onde predominam pastagens (Figura 2). 


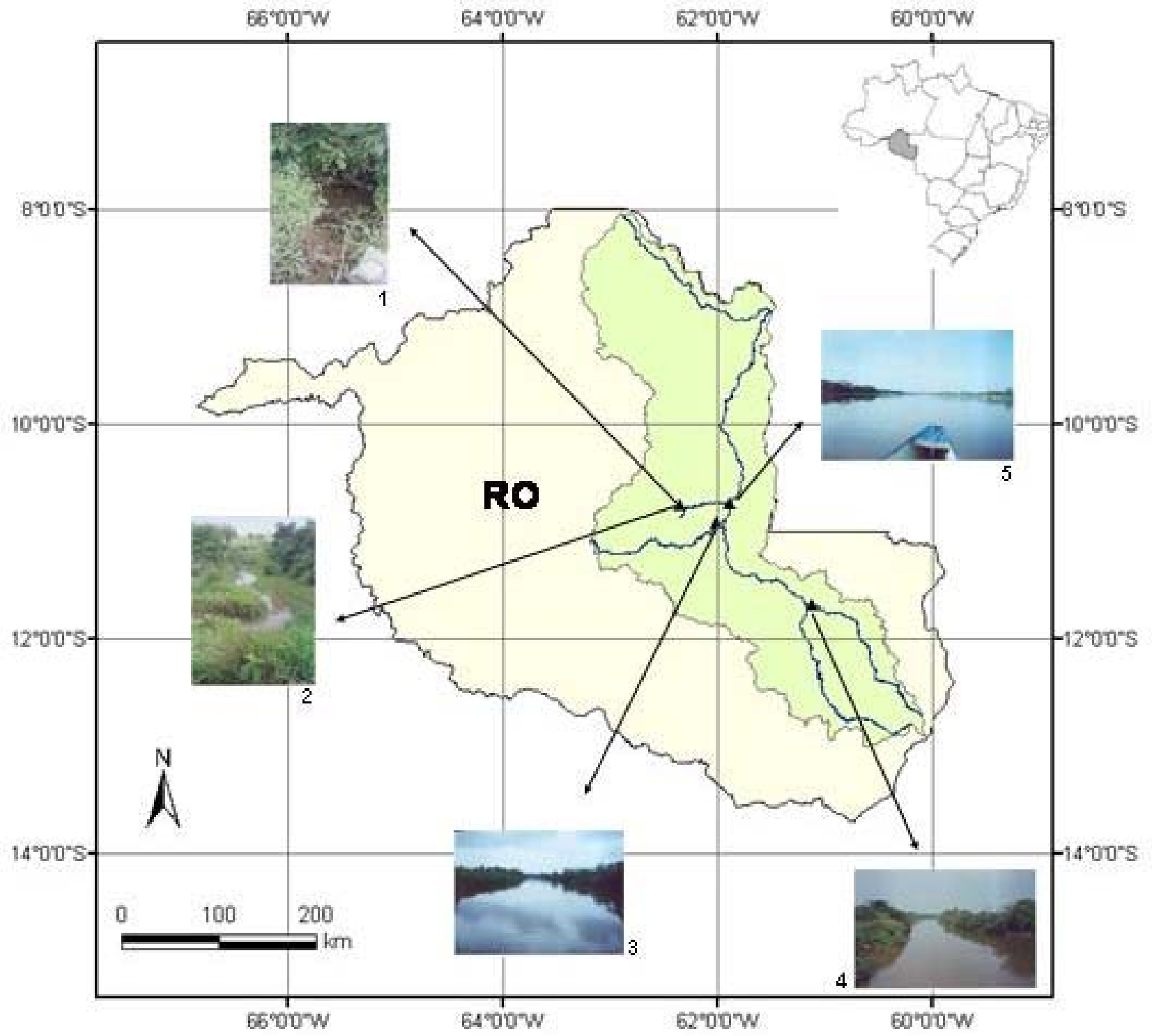

Figura 1 - Identificação dos pontos amostrados e delimitação da bacia do rio Ji-Paraná. 1 - Igarapé Boa Vista - floresta (BVF), 2 - Igarapé Boa Vista - pastagem (BVP), 3 - Rio Urupá (URU), 4 - Rio Comemoração (COM) e, 5 - Rio JiParaná (JIP) 


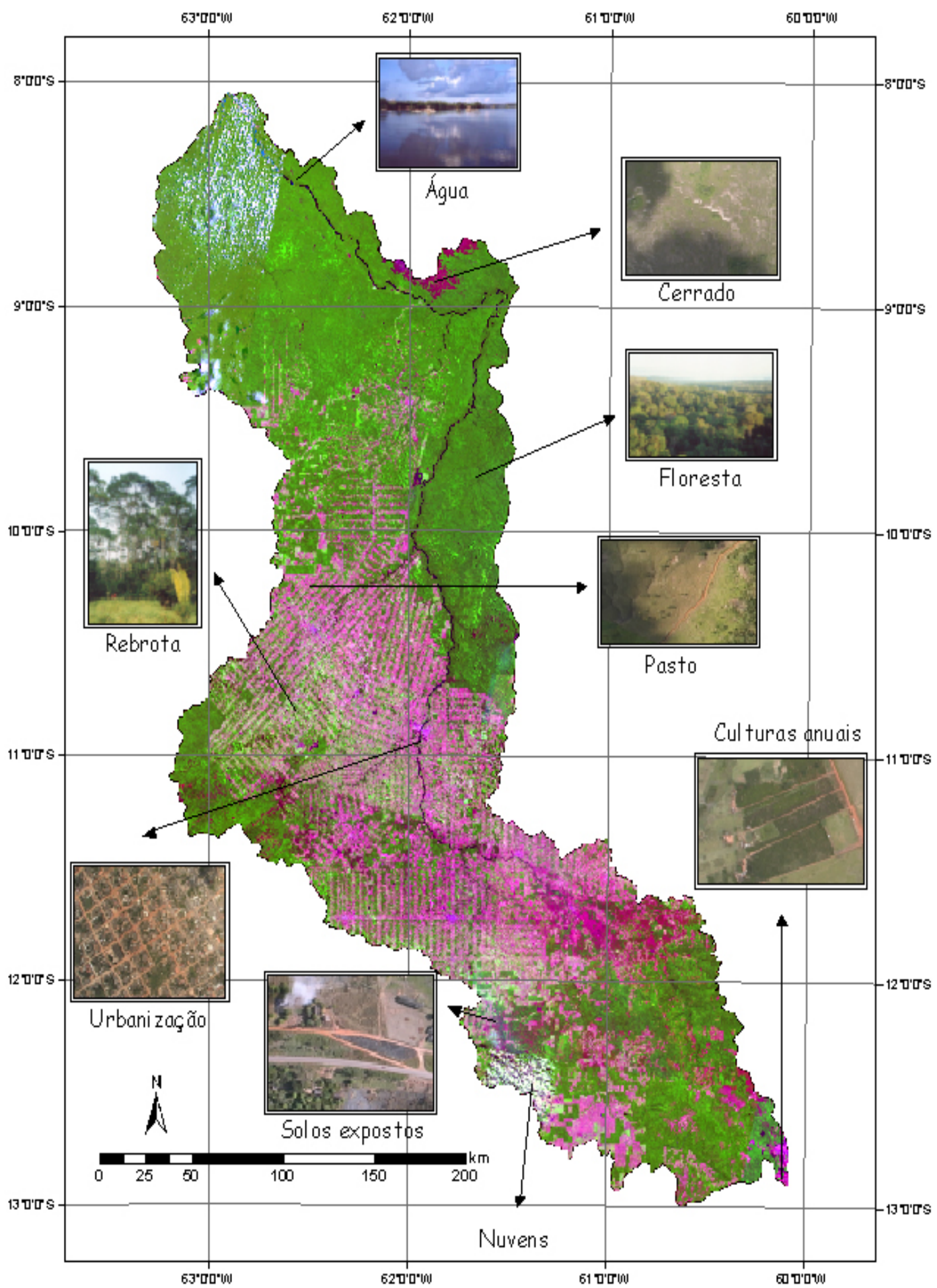

Figura 2 - Mapa de uso da terra na bacia do rio Ji-Paraná, conforme observado em imagens de julho e setembro de 1999 obtidas pelo satélite Landsat-7, ETM+. Dados obtidos do Tropical Rainforest West Inventory 
A bacia apresenta uma topografia relativamente plana, com altitudes em torno de 150 a $600 \mathrm{~m}$ acima do nível do mar. Os rios de $1^{\mathrm{a}}$ a $3^{\mathrm{a}}$ ordens, denominados regionalmente de igarapés, são predominantes na paisagem, apresentando uma área de aproximadamente 27.497 km de extensão. O canal principal do rio Ji-Paraná apresenta um comprimento total de 972 km e largura que varia de 150 a 500 m (Ballester et al., 2003).

Os solos do estado de Rondônia são muito antigos, altamente intemperizados, com baixa concentração de nutrientes, alta acidez, baixa capacidade de troca catiônica e condições pobres de drenagem. Porém, em 60\% da área da bacia do rio Ji-Paraná ocorrem solos eutróficos, predominantemente latossolos e podzólicos, com uma característica favorável para o desenvolvimento de atividades agrícolas (Krusche, com. pess.).

A distribuição dos tipos de solos na bacia do rio Ji-Paraná é bastante heterogênea, com solos muito arenosos e pobres em cátions mais ao norte e ao sul e manchas isoladas de solos com maiores teores de argila e mais ricos em cátions na porção central. Os tipos de solos mais comuns são os Latossolos e Argissolos, com 47\% e $24 \%$, respectivamente, da área total da bacia de drenagem, e o restante está distribuído entre os Neossolos Quartzarênicos (14\%), Nitossolos (13\%) e Cambissolos (2\%) (Ballester et al., 2003), Figura 3. 


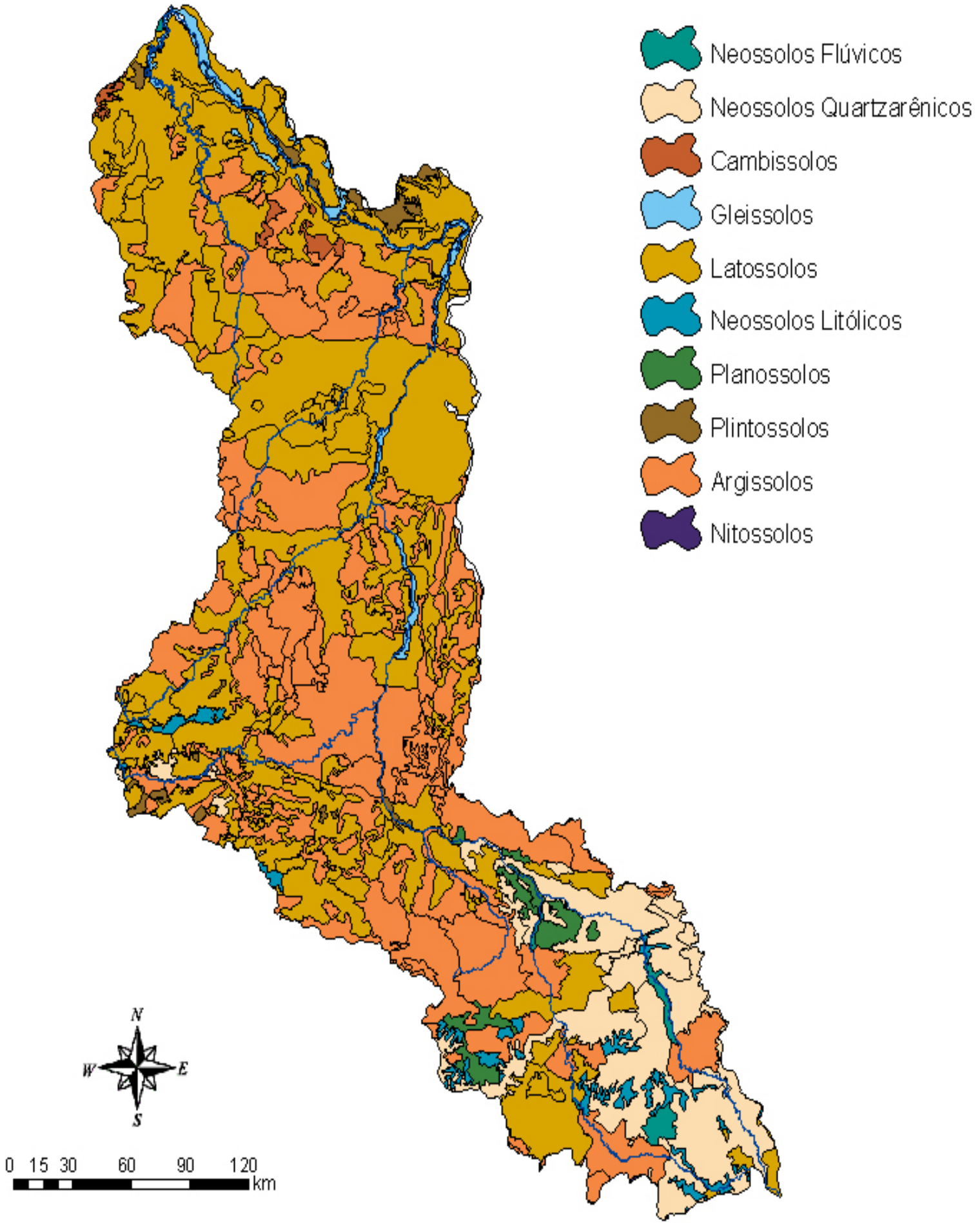

Figura 3 - Mapa de unidades de solos da bacia do rio Ji-Paraná (EMBRAPA, 1983), modificado para o novo sistema de classificação de solos (EMBRAPA, 1999) 
Em geral, estes solos apresentam uma concentração média de 57,9\% de areia, $32,8 \%$ de argila e 9,3\% de silte nos primeiros 15 ou $20 \mathrm{~cm}$. Segundo Ballester et al. (2003), devido às baixas concentrações de hidrogênio $\left(\mathrm{H}^{+}\right)$e alumínio $\left(\mathrm{Al}^{2+}\right)$ é possível observar altos valores de saturação de bases; $40 \%$ da bacia é coberta por solos distróficos (saturação por bases menor que 50\%) e 60\% coberto por solos eutróficos (saturação por bases maior que 50\%), (Figura 4).

Segundo a classificação de Köppen, o estado de Rondônia possui um clima do tipo Aw - Clima Tropical Chuvoso. A bacia do rio Ji-Paraná pode ser dividida entre os grupos Am, mais ao norte do estado e Aw, mais ao sul. Apresenta regime pluviométrico médio anual que varia entre 1.400 a $2.500 \mathrm{~mm}$, e temperatura média anual entre 24 e 26 ${ }^{\circ} \mathrm{C}$, com temperaturas máximas entre 30 e $34{ }^{\circ} \mathrm{C}$, e mínimas entre 17 e $23{ }^{\circ} \mathrm{C}$ (Atlas Geoambiental de Rondônia, 2002). As maiores precipitações ocorrem entre os meses de Dezembro a Março, enquanto que o período de estiagem se estende de Julho a Setembro. 


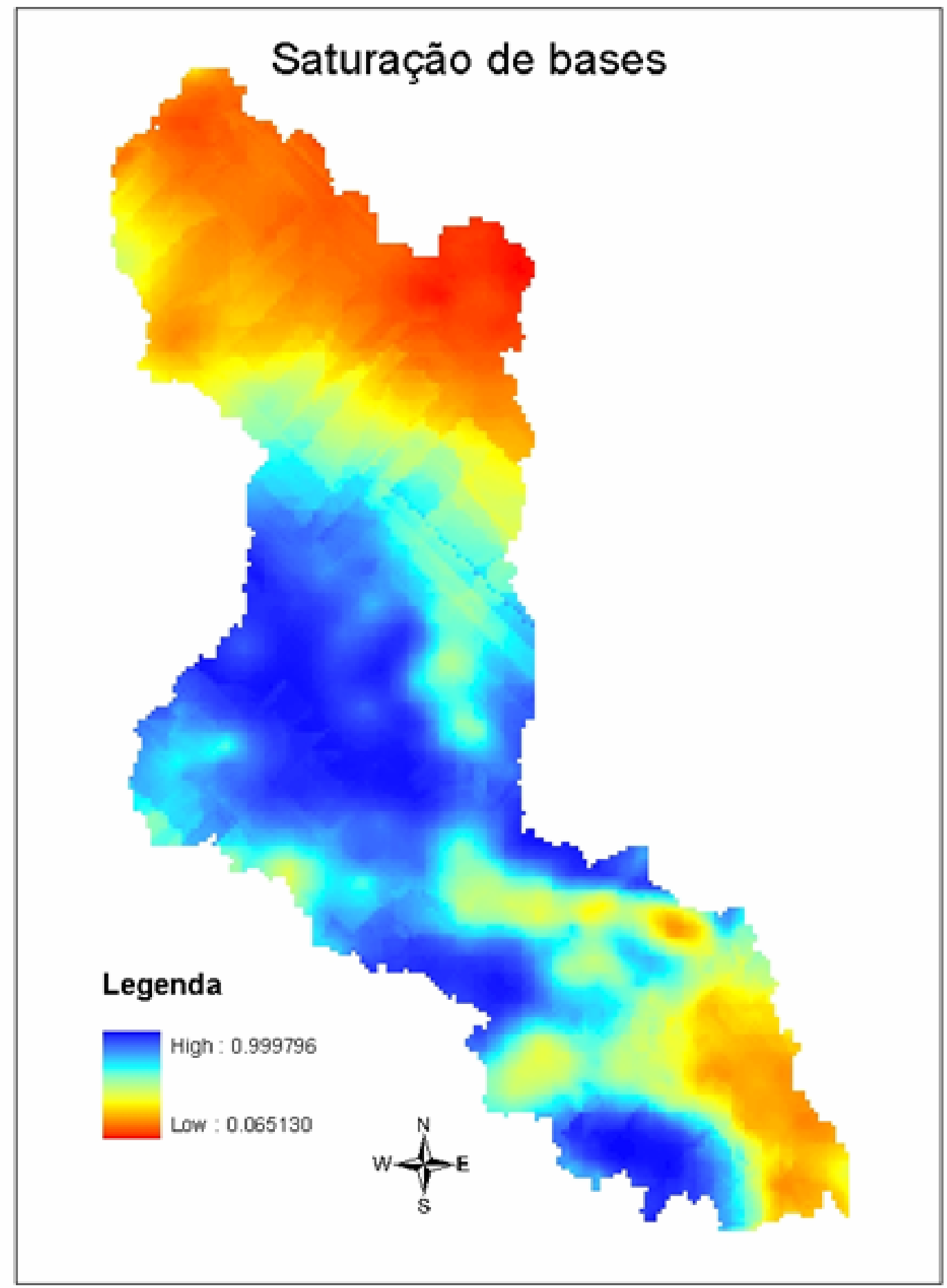

Figura 4 - Mapa de saturação de bases, criado a partir dos dados do SIGTERON. Foram utilizados os dados de 1041 perfis de solo, a uma profundidade de $20 \mathrm{~cm}$. Para obtenção de uma superfície contínua foi aplicada análise geoestatística 
A hidrógrafa do rio Ji-Paraná, na cidade de Ji-Paraná, baseada nas médias históricas de descarga dos anos 1978 a 2003 (fonte: Agência Nacional de Águas - ANA), é apresentada na Figura 5. As setas em vermelho indicam as datas em que foram feitas as amostragens, representativas, respectivamente dos períodos de seca (agosto/setembro), enchente (novembro/dezembro) e cheia (janeiro/fevereiro) (Figura 5).

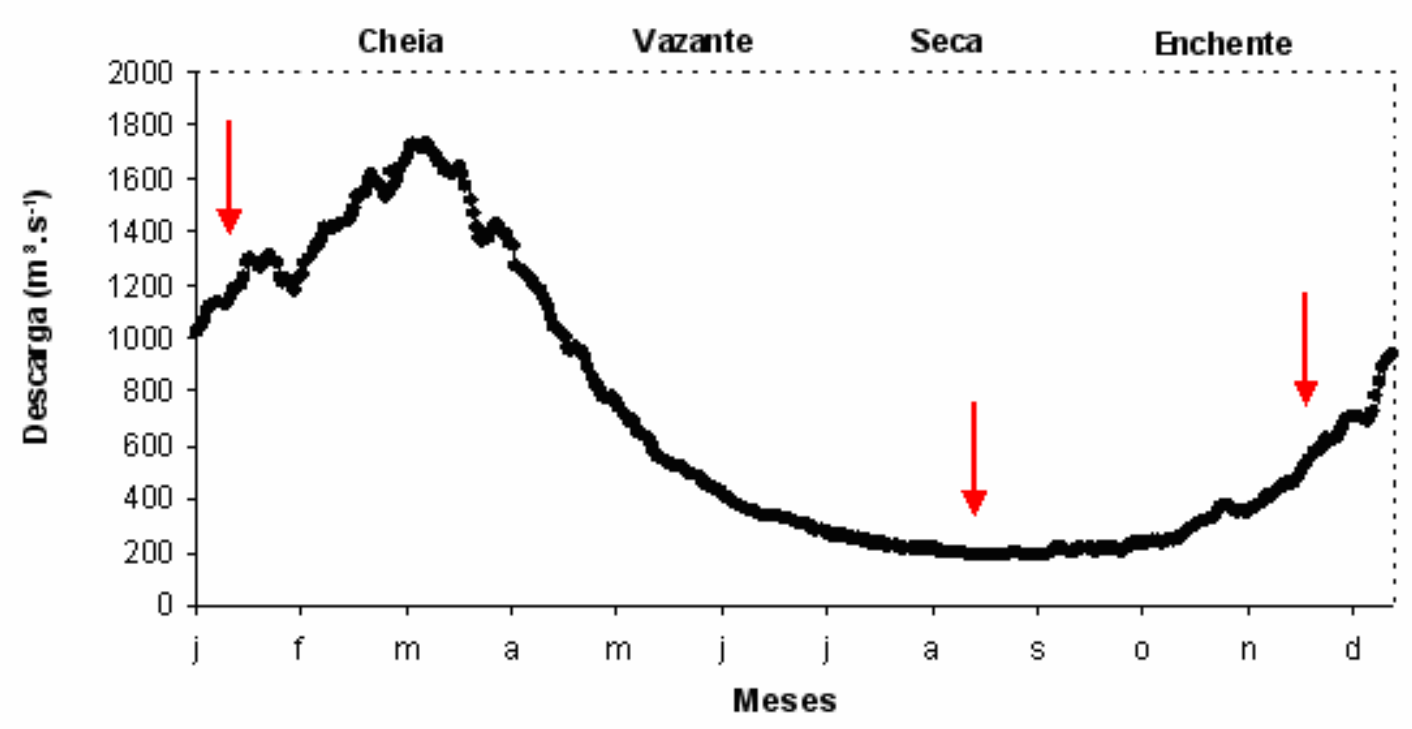

Figura 5 - Média das descargas diárias do rio Ji-Paraná, na cidade de Ji-Paraná (1978 a 2003), Fonte: Agência Nacional de Águas - ANA. As setas indicam os períodos em que foram efetuadas as amostragens

O Igarapé Boa Vista está localizado na parte central da bacia de drenagem do rio Ji-Paraná. Sua nascente localiza-se em uma pastagem e, após percorrer alguns fragmentos de floresta, desemboca no rio Ji-Paraná, à jusante da cidade de Ji-Paraná. A distância entre os dois pontos amostrados neste igarapé foi de aproximadamente $700 \mathrm{~m}$. O ponto amostrado na pastagem será referido, daqui em diante, como BVP (Boa Vista Pastagem), e o ponto amostrado na floresta como BVF (Boa Vista Floresta). 
O rio Urupá (daqui em diante referido como URU), também localizado na porção central da bacia do rio Ji-Paraná, apresenta os solos mais ricos desta, drenando áreas muito férteis. Nesta parte da bacia, pode ser encontrada uma mistura de rochas de origem vulcânica e sedimentar (Scandolara et al., 1998).

O rio Comemoração (daqui em diante referido como COM) é um dos principais formadores do rio Ji-Paraná, drenando a parte leste da bacia. Este rio percorre um setor com baixo impacto antropogênico em suas cabeceiras e com grau moderado de alteração na região da sua desembocadura no rio Ji-Paraná (Tabela 1). Sua nascente está situada em substrato sedimentar (arenitos, argilitos e siltitos), enquanto que, no setor mais à jusante, podem ser observados afloramentos rochosos mais recentes (basaltos e gabros), constituintes da Formação Basalto Anari.

O rio Ji-Paraná (daqui em diante referido como JIP) é formado pela confluência dos rios Pimenta Bueno e Comemoração, tendo sua bacia localizada sobre rochas metamórficas (gnaisses e kinzigitos). Devido à proximidade da BR-364 e à existência de solos mais ricos em sua região central e, portanto, mais propícios para cultivo, drena a área mais povoada do estado.

Na Tabela 1 apresentam-se os graus de impacto antropogênico para cada subbacia estudada, de acordo com classificação de Ballester et al. (2003). Com base no percentual da área das sub-bacias ocupado por pastagens, estes autores definiram os graus de impacto como: (1) baixo (0-15\% da área com pastagem); (2) médio (15-30\%); (3) alto (30-50\%) e muito alto (50-75\%). 
Tabela 1. Identificação dos graus de impacto antropogênico das bacias dos rios amostrados

\begin{tabular}{ccccc}
\hline $\begin{array}{c}\text { Ponto } \\
\text { Amostrado }\end{array}$ & Rio & $\begin{array}{c}\text { Ordem } \\
\text { dos rios }\end{array}$ & Local & $\begin{array}{c}\text { Grau de Alteração } \\
\text { do Uso do Solo }\end{array}$ \\
\hline COM & Comemoração & $5^{\mathrm{a}}$ & Pimenta Bueno & Médio \\
URU & Urupá & $5^{\mathrm{a}}$ & Ji-Paraná & Muito Alto \\
JIP & Ji-Paraná & $6^{\mathrm{a}}$ & Ji-Paraná & Alto \\
BVP & Ig. Boa Vista Pastagem & $1^{\mathrm{a}}$ & Ouro Preto d'Oeste & Alto \\
BVF & Ig. Boa Vista Floresta & $1^{\mathrm{a}}$ & Ouro Preto d'Oeste & Baixo \\
\hline
\end{tabular}

O nível de impacto foi determinado utilizando-se a porcentagem de pastagem em cada setor, e classificado como: baixo, 0-15 \%; médio, 15-30 \%; alto, 30-50 \%; muito alto, $50-75 \%$

\subsection{Métodos Amostrais}

As amostragens foram efetuadas no meio do canal principal dos rios, a uma profundidade equivalente a $60 \%$ da total ${ }^{1}$, (Hauer \& Lamberti, 1996), empregando-se uma bomba de submersão. As amostras foram bombeadas através de uma peneira de 63 $\mu \mathrm{m}$ de porosidade nominal e armazenadas em galões de plástico de $10 \mathrm{~L}$, previamente descontaminados. Para evitar alterações durante o transporte, estes galões foram acondicionados dentro de isopores revestidos com papel de alumínio e mantidos assim até o início dos experimentos em laboratório, efetuados no mesmo dia da amostragem. O material retido na peneira, que constitui a fração de sedimentos em suspensão grossos, foi lavado da mesma para dentro de frascos de policarbonato de $250 \mathrm{~mL}$, para transporte ao laboratório. Ainda no campo, mediram-se, com equipamentos portáteis, $\mathrm{pH}$, condutividade elétrica e temperatura das águas (Figura 6). No laboratório, alíquotas de

\footnotetext{
${ }^{1}$ Em estudo realizado por Morisawa (1988), a $60 \%$ da profundidade total se encontra a maior velocidade da corrente e o maior potencial para carreamento de sedimentos.
} 
cada amostra foram filtradas para análise posterior das concentrações de carbono orgânico (COD) e íons dissolvidos.

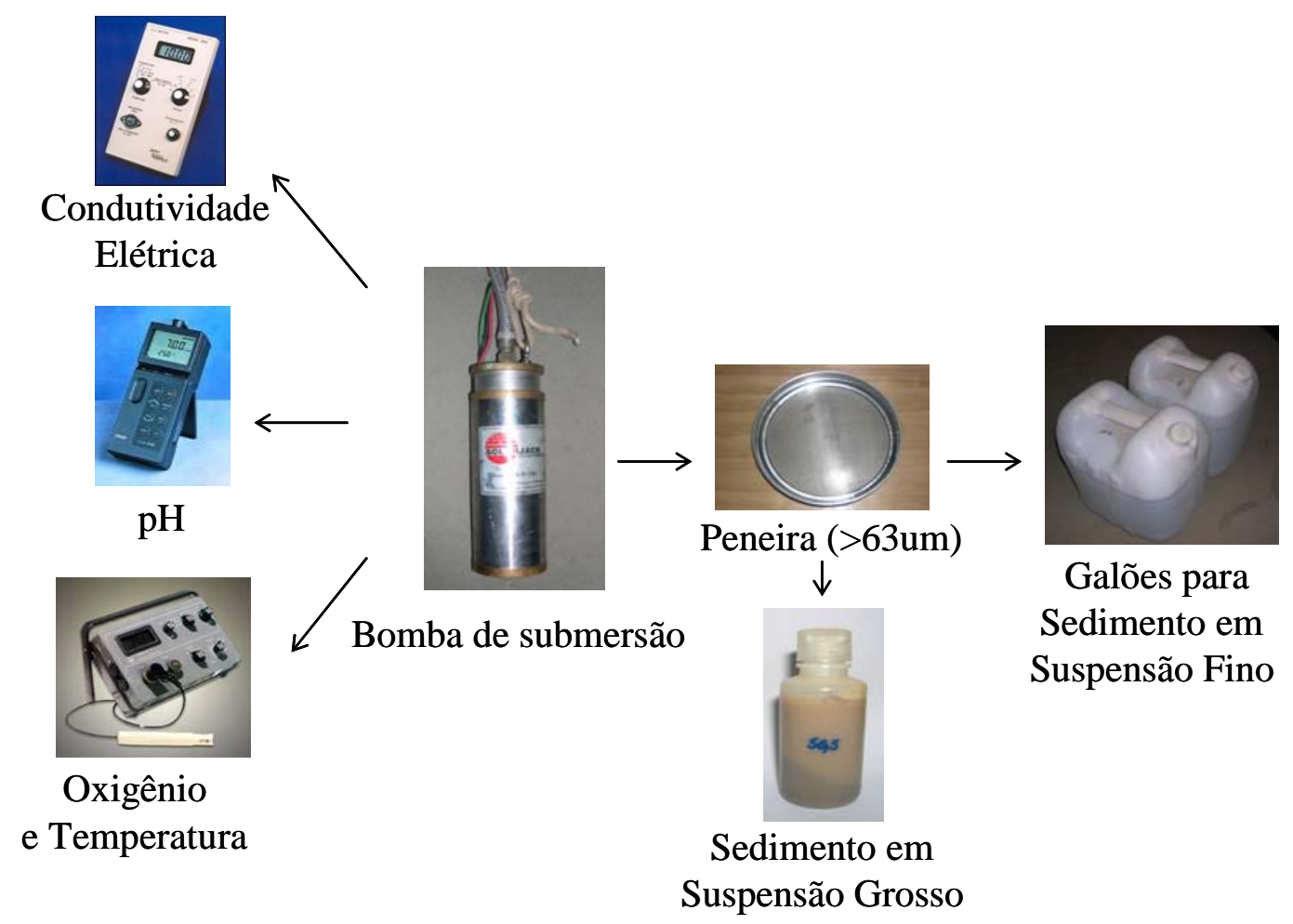

Figura 6 - Ilustração do esquema utilizado em campo para as amostragens das águas dos rios

\subsection{Experimentos de enriquecimento com sedimentos em suspensão}

Para testar a hipótese deste trabalho, foram realizados experimentos em laboratório, nos quais amostras das águas dos rios tiveram suas concentrações de sedimentos em suspensão artificialmente incrementadas e foram posteriormente incubadas no escuro. O consumo de oxigênio durante estas incubações foi utilizado para calcular as taxas respiratórias e, finalmente, comparar suas variações em função das alterações nas concentrações de sedimentos em suspensão. 


\subsubsection{Sedimentos em Suspensão Grossos (SSG)}

No caso dos sedimentos em suspensão grossos, empregou-se o material obtido ainda no campo, peneirado durante a amostragem. Uma vez que o procedimento para recolher este material nos frascos de $250 \mathrm{~mL}$ implicou na lavagem da peneira, com água ultra-pura, inicialmente procedeu-se à sua homogeneização por agitação manual. Posteriormente, empregando pipetador, alíquotas desta solução foram transferidas para 3 garrafas (replicatas) de vidro âmbar de 2,5 L, que continham a amostra de água do rio correspondente, já peneirada no campo, isto é, livre de sedimentos em suspensão grossos. Outros 3 frascos com a mesma amostra foram mantidos sem adição destes sedimentos, para servir como controle. Antes da transferência das amostras, armazenadas em galões de plástico, todas foram homogeneizadas por 15 minutos, a fim de evitar erros decorrentes da decantação dos sedimentos em suspensão finos, Figura 7.

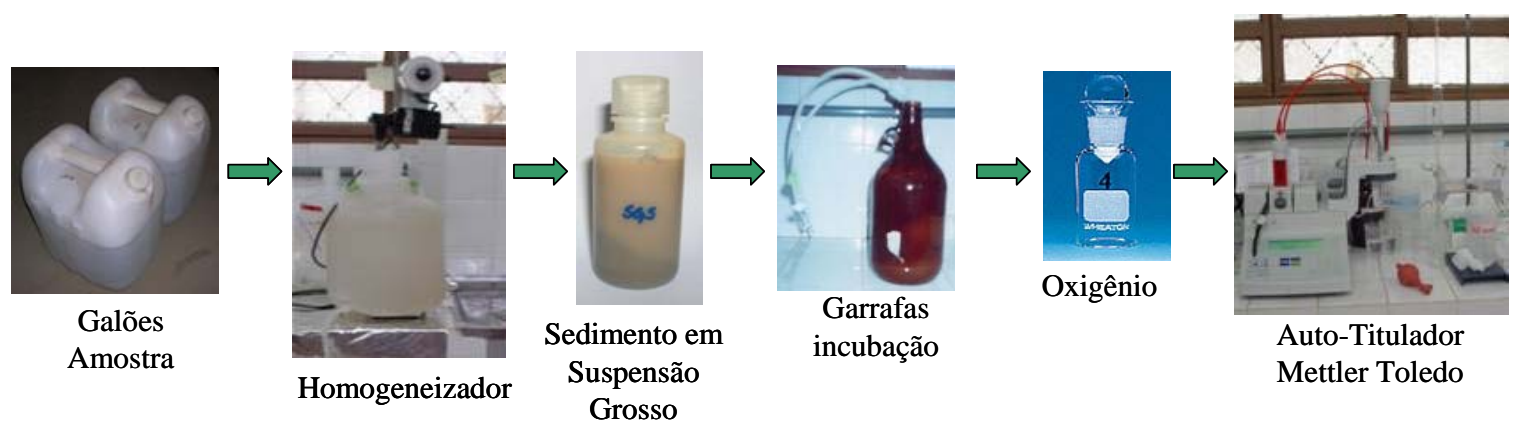

Figura 7 - Ilustração dos experimentos adicionados Sedimentos em Suspensão Grossos

Como não era possível determinar as concentrações originais de sedimentos, pois os experimentos deviam ser feitos no dia da coleta (para evitar alterações na biota destas amostras), optou-se por adicionar volumes aproximadamente fixos, fazendo com que as massas de sedimentos em suspensão grossos adicionados às amostras fossem distintas em cada caso, conforme a Tabela 2. Para quantificar estas massas, alíquotas de mesmo volume foram retirados do concentrado e filtrados em filtros de nitrato de 
celulose, previamente secos e pesados. Após a filtração estes filtros foram novamente secos e pesados e o cálculo da massa foi efetuado pela diferença entre os pesos iniciais e finais. Todas as amostras foram incubadas no escuro, conforme descrito adiante no item 2.3.3.

Uma vez que as massas de sedimentos adicionados foram distintas para cada amostra, para a análise comparativa dos resultados, efetuou-se a normalização dos dados, tendo sempre como referência a menor massa utilizada.

Tabela 2. Massas de sedimentos em suspensão grossos (SSG, em mg) adicionados às amostras de águas de rios de Rondônia

\begin{tabular}{cc}
\hline Período/Locais Amostrados & $\begin{array}{c}\text { Massa de SSG adicionada } \\
\text { (mg) }\end{array}$ \\
\hline Seca & 6,85 \\
Rio Comemoração & 21,86 \\
Rio Urupá & 91,14 \\
Rio Ji-Paraná & 13,57 \\
Ig. Boa Vista (past) & 24,24 \\
Ig. Boa Vista (flo) & \\
& \\
Enchente & 400,17 \\
Rio Comemoração & 259,59 \\
Rio Urupá & 98,63 \\
Rio Ji-Paraná & 38,48 \\
Ig. Boa Vista (past) & 31,78 \\
Ig. Boa Vista (flo) & \\
Cheia & \\
Rio Comemoração & 209,72 \\
Rio Urupá & 995,19 \\
Rio Ji-Paraná & 2245,51 \\
Ig. Boa Vista (past) & 269,0 \\
Ig. Boa Vista (flo) & \\
\hline x- não amostrado &
\end{tabular}




\subsubsection{Sedimentos em Suspensão Finos (SSF)}

No caso dos sedimentos em suspensão finos, adotou-se uma metodologia distinta para testar o efeito do incremento de suas concentrações nas taxas respiratórias. Empregando um sistema de ultrafiltração da marca Millipore (modelo Pellicon II), com filtro de porosidade de 0,1 $\mu \mathrm{m}$ (Benner, 1991), as amostras já peneiradas, isto é, livres de sedimentos em suspensão grossos, foram pré-concentradas antes de serem incubadas. O sistema de ultrafiltração oferece a vantagem de permitir a visualização, no seu reservatório, da amostra que está sendo concentrada. Como neste caso também não era possível determinar a concentração inicial destes sedimentos, pelas razões já citadas, procedeu-se à análise da turbidez da amostra, à medida que era pré-concentrada. Assim, quando a amostra apresentava turbidez elevada, indicando um fator de pré-concentração aparentemente satisfatório, encerrava-se o processo e as amostras eram incubadas da mesma maneira descrita para os sedimentos em suspensão grossos, isto é, com 3 replicatas (Figura 8).

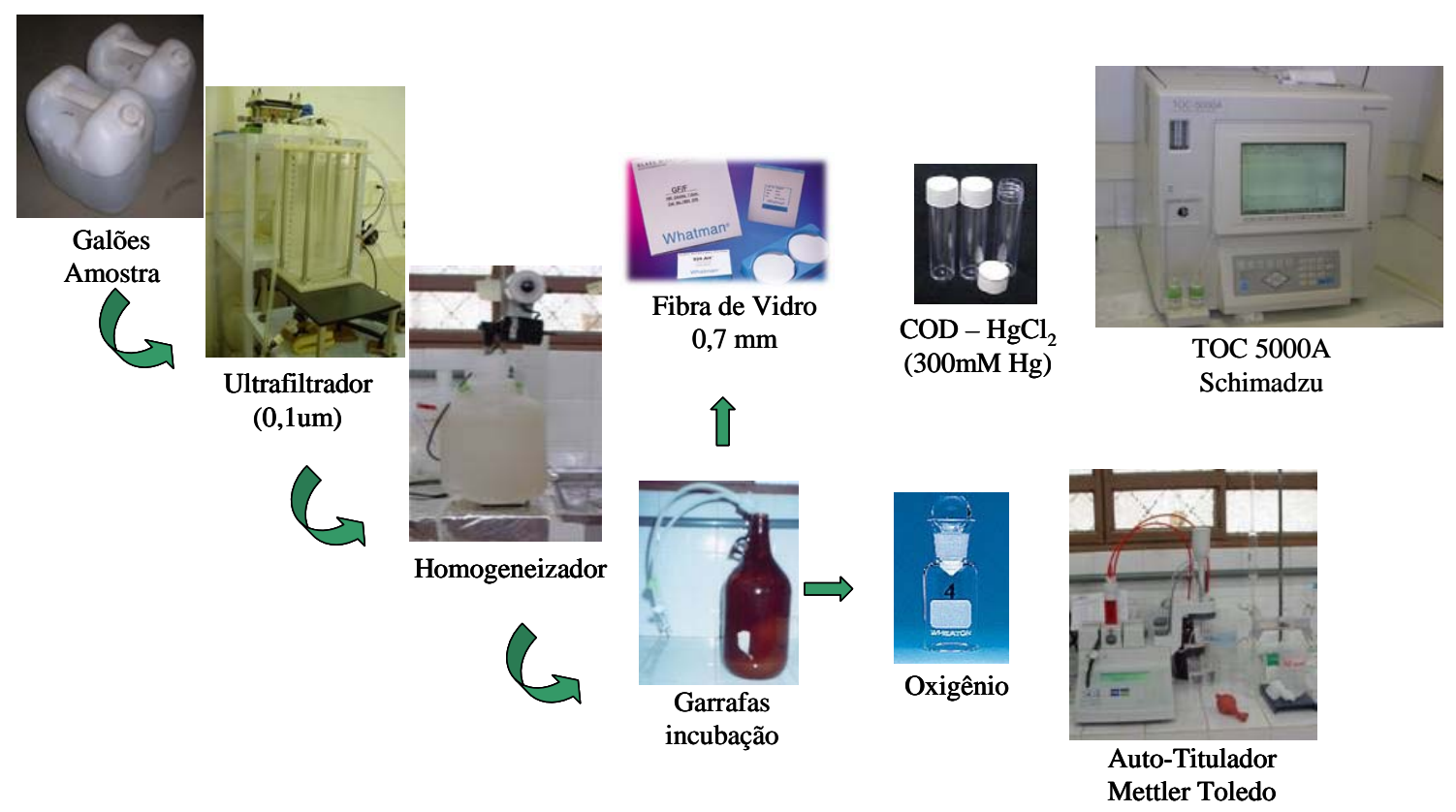

Figura 8 - Ilustração dos experimentos enriquecidos com Sedimentos em Suspensão Finos 
As réplicas utilizadas como controle foram às mesmas do experimento com sedimentos grossos. Os fatores de pré-concentração variaram de 4 a 9, resultando em aumentos das concentrações de sedimentos em suspensão finos variados a cada caso, conforme a Tabela 3. A determinação das concentrações foi feita de forma análoga à descrita para os sedimentos em suspensão grossos. A análise comparativa dos resultados foi feita tendo-se como referência o menor fator de concentração.

Tabela 3. Concentrações dos sedimentos em suspensão finos (SSF, em mg/L), nas amostras de água de rios, antes e após o procedimento de pré-concentração por ultrafiltração

\begin{tabular}{|c|c|c|c|}
\hline Período/Locais Amostrados & $\begin{array}{l}\text { Controle } \\
\text { (mg/L) }\end{array}$ & $\begin{array}{c}\text { Concentrado } \\
\text { (mg/L) }\end{array}$ & $\begin{array}{c}\text { Fator de } \\
\text { enriquecimento }\end{array}$ \\
\hline \multicolumn{4}{|l|}{ Seca } \\
\hline Rio Comemoração & 5,55 & 15,2 & $2,7 x$ \\
\hline Rio Urupá & 4,45 & 12,8 & $2,8 x$ \\
\hline Rio Ji-Paraná & 11,9 & 39,8 & $3,3 x$ \\
\hline Ig. Boa Vista (past) & 4,6 & 5,83 & $1,7 \mathrm{x}$ \\
\hline Ig. Boa Vista (flo) & 7,35 & 5,56 & $(-) 0,7 x$ \\
\hline \multicolumn{4}{|l|}{ Enchente } \\
\hline Rio Comemoração & 10,25 & 84,5 & $8,2 \times$ \\
\hline Rio Urupá & 28,4 & 114,8 & $4,0 \times$ \\
\hline Rio Ji-Paraná & 28,4 & 141,2 & $5,0 \times$ \\
\hline Ig. Boa Vista (past) & 16,9 & 75,86 & $4,5 \mathrm{x}$ \\
\hline Ig. Boa Vista (flo) & 7,4 & 16,1 & $2,2 \mathrm{x}$ \\
\hline \multicolumn{4}{|l|}{ Cheia } \\
\hline Rio Comemoração & 41,4 & 235,6 & $5,7 x$ \\
\hline Rio Urupá & 75,6 & 184,8 & $2,4 \times$ \\
\hline Rio Ji-Paraná & 35,3 & 110,5 & $3,1 \times$ \\
\hline Ig. Boa Vista (past) & 3,5 & 3,7 & $1,1 \mathrm{x}$ \\
\hline Ig. Boa Vista (flo) & $\mathrm{x}$ & $\mathrm{x}$ & $\mathrm{x}$ \\
\hline
\end{tabular}




\subsubsection{Incubações no escuro para determinar o consumo de oxigênio}

Para obter as taxas respiratórias, partiu-se do pressuposto que, no escuro, não ocorre fotossíntese, mas os processos respiratórios, que consomem oxigênio, prosseguem normalmente. Assim, amostras de águas de rios incubadas no escuro devem ter suas concentrações de oxigênio dissolvido progressivamente diminuídas, à medida que são mantidas sob tais condições. As diferenças entre as concentrações iniciais e finais representam a taxa respiratória para o período total de incubação.

Para testar possíveis alterações nestas taxas ao longo de intervalos distintos, foram feitas incubações por 24 e 48 hs, o que acarretou na necessidade de um desenho experimental específico. As amostras foram incubadas em frascos de 2,5 L de vidro âmbar e tampadas com rolhas transpassadas por dois tubos de teflon, ambos contendo torneiras nas suas extremidades localizadas fora dos frascos. Um destes tubos teve sua extremidade interna ao frasco acoplada a um saco plástico, do tipo utilizado para coleta de gases, ao passo que a extremidade do outro tubo conectava-se diretamente à amostra líquida (Figura 9). Desta forma, quando foram retiradas as alíquotas para determinar as concentrações de oxigênio dissolvido, após 24 horas de incubação, o volume de amostra retirada (50 mL) foi substituído dentro do frasco de incubação, adicionando-se água de torneira à parte interna do saco de amostragem de gases. Desta forma, evitou-se entrada de ar no sistema. As concentrações de oxigênio dissolvido foram determinadas pelo método de Winkler, conforme descrito a seguir, no item 2.3.4. 


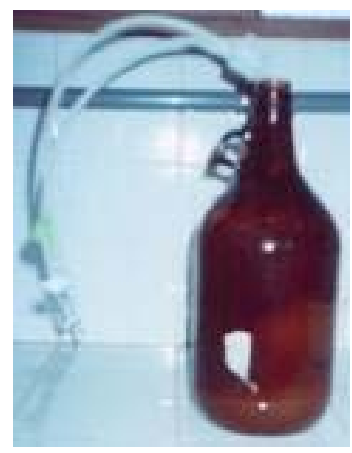

Figura 9 - Garrafas utilizadas nas incubações

A Figura 10 mostra, de maneira esquemática, como foram distribuídas as réplicas nas diversas garrafas incubadas. Para o controle e cada um dos dois tratamentos (sedimentos finos ou grossos) foram feitas 3 réplicas, das quais foram retiradas duas réplicas após 24 horas e outras duas após 48 horas de incubação, totalizando 18 amostras para cada intervalo de tempo. Todas as garrafas foram mantidas dentro de caixas revestidas de alumínio, no escuro e com temperatura controlada.

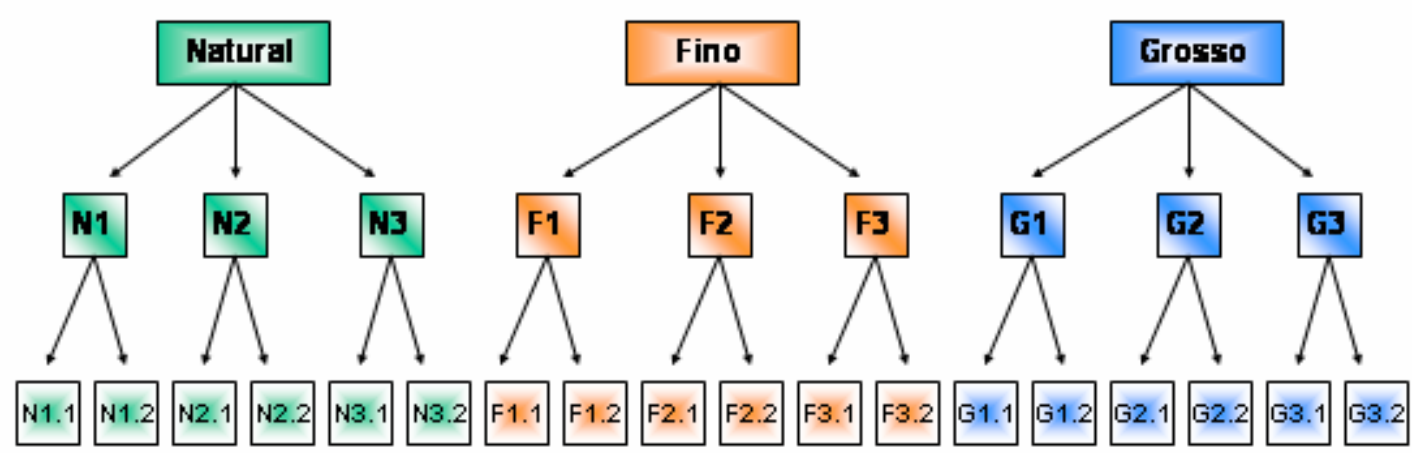

Figura 10 - Organograma das amostras retiradas para determinação das concentrações de Oxigênio Dissolvido nos experimentos de adição de sedimentos. $\mathrm{N}_{\mathrm{x}}=$ Controle, $\mathrm{F}_{\mathrm{X}}=$ Amostras pré-concentradas com sedimentos em suspensão finos e $G_{x}=$ Amostras que receberam sedimentos em suspensão grossos 


\subsubsection{Determinação das taxas respiratórias}

Para a determinação das taxas respiratórias foi utilizado o método do consumo de oxigênio em alíquotas incubadas no escuro (Devol et al., 1995; Wetzel \& Likens, 1991), sendo as mesmas calculadas de acordo com a equação:

$$
\mathbf{T R}=\left(\mathbf{O D} \mathbf{D}_{\text {inicial }}-\mathbf{O D}_{\text {final }}\right) / \mathbf{t} \quad \text { onde }
$$

Taxa Respiratória = consumo de oxigênio, em $\mu \mathrm{M} \cdot \mathrm{h}^{-1}$;

$\mathrm{OD}_{\text {inicial }}=$ concentração de oxigênio dissolvido no início da incubação, em $\mu \mathrm{M}$;

$\mathrm{OD}_{\text {final }}=$ concentração de oxigênio dissolvido no final da incubação, em $\mu \mathrm{M}$;

$\mathrm{t}$ = tempo de incubação, em horas.

As concentrações de oxigênio dissolvido foram determinadas em alíquotas de 50 $\mathrm{mL}$, retiradas nos frascos de incubação e analisadas imediatamente, utilizando o método de Winkler (Wetzel \& Likens, 1991) em um titulador automatizado da marca MettlerToledo, modelo DL77.

\subsection{Determinação das concentrações de carbono orgânico dissolvido (COD)}

Para avaliar o efeito da adição de sedimentos nas concentrações de carbono orgânico dissolvido, que são substratos dos processos respiratórios, suas concentrações foram determinadas em todos os frascos incubados, no início das incubações. Uma alíquota foi retirada dos frascos de vidro com uma seringa de $60 \mathrm{~mL}$. Nesta foi acoplado um suporte de filtração para filtros de 25 mm de diâmetro. Filtros de fibra de vidro do 
tipo $\mathrm{GF} / \mathrm{F}$ (porosidade nominal de 0,7 $\mu \mathrm{m}$ ), previamente calcinados a uma temperatura de $500{ }^{\circ} \mathrm{C}$ por 5 horas, foram utilizados nestes suportes para filtrar a amostra. Após filtração, o material dissolvido foi armazenado em frascos de vidro pré-calcinados como acima, e com tampas revestidas internamente com teflon, e preservado com $\mathrm{HgCl}_{2}$ (concentração final de $300 \mu \mathrm{M}$ de $\mathrm{Hg}$ ). Em laboratório, estas amostras foram acidificadas até pH menor que 1 e o carbono inorgânico, assim convertido em $\mathrm{CO}_{2}$, foi extraído mediante borbulhamento com ar sintético.

Após este pré-tratamento, as amostras foram analisadas em equipamento específico, da marca Shimadzu, modelo TOC5000A, no qual o carbono é queimado a $680{ }^{\circ} \mathrm{C}$ e o $\mathrm{CO}_{2}$ resultante quantificado por absorção em detector de infravermelho não dispersivo. As concentrações foram obtidas por comparação com padrões externos e o desvio-padrão das médias de cada determinação mantido sempre inferior a $1 \%$. Os equipamentos utilizados para as amostragens efetuadas em laboratório encontram-se na Figura 11.
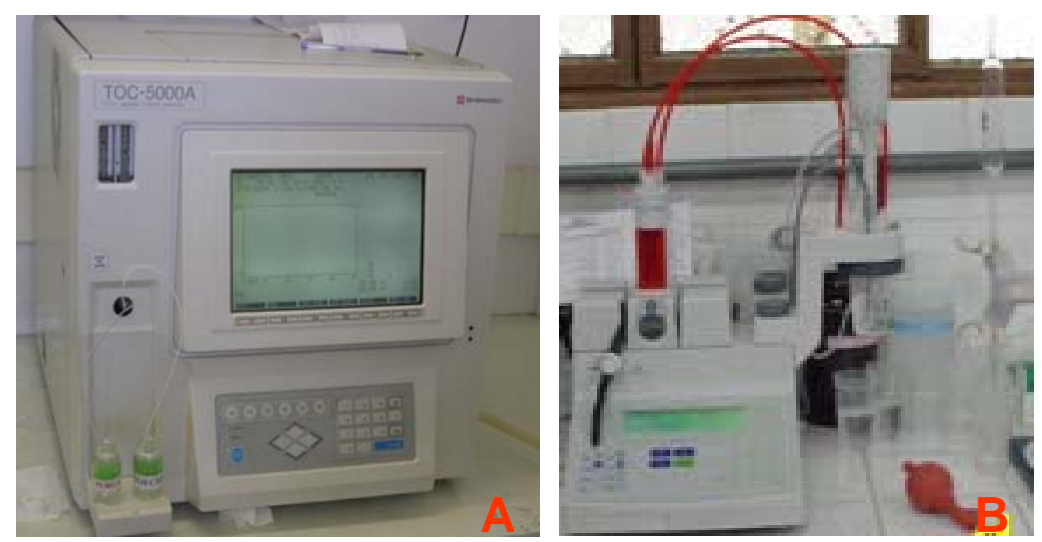

Figura 11 - Equipamentos utilizados em laboratório. A - Analisador de Carbono Shimadzu modelo TOC 5000A, B - Auto-Titulador da marca MettlerToledo, modelo DL77 


\subsection{Análise Estatística}

Os resultados obtidos neste estudo, além de apresentarem interdependência, não apresentaram distribuição normal e, portanto, as análises estatísticas foram efetuadas com testes não-paramétricos, por serem considerados testes mais robustos, empregando o software STATISTICA, versão 6, StatSoft, Inc. (2004).

Para avaliar se os valores médios das alterações nas taxas respiratórias foram relacionadas com as distintas adições de sedimentos, utilizou-se o teste de Correlação de Spearman. Os valores foram considerados significativos para $\mathrm{p}<0,05$. 


\section{RESULTADOS E DISCUSSÃO}

\subsection{Variações sazonais e espaciais das concentrações de carbono orgânico dissolvido e do pH}

O carbono exerce um importante papel em inúmeros processos aquáticos (Wetzel, 1992), servindo como fonte de energia para o sistema. A matéria orgânica dissolvida é um forte agente complexador de metais, como ferro, cobre, alumínio, zinco e mercúrio, podendo afetar a solubilidade, o transporte e a toxicidade dos mesmos (Schnitzer \& Khan, 1972; Reuter \& Perdue, 1977; Baker \& Schofield, 1982; Buffle, 1984). O aumento nas concentrações de carbono orgânico dissolvido (COD) pode também contribuir para a acidificação da água, alterando o sistema de tamponamento do meio aquático (Oliver et al., 1983; Eshleman \& Hemond, 1985; Thurman, 1985; Kerekes et al., 1986), e afetando a distribuição de íons entre a água e os sedimentos (BaasBecking \& Moore, 1959; Jenne, 1975). Segundo Aitkenhead et al. (1999), a concentração de COD pode ser influenciada ainda pela fisiografia da bacia hidrográfica, precipitação, vegetação e cobertura do solo.

As concentrações de carbono orgânico dissolvido nas águas dos rios analisados, em geral, foram significativamente menores nos períodos de seca (Figura 12), com a exceção daquelas do igarapé Boa Vista. Apesar de, no período da cheia, estas concentrações não terem sido determinadas na parte deste igarapé que fica na floresta, na parte localizada na pastagem observou-se um comportamento inverso, com concentrações menores neste período, apesar de estatisticamente não significativas. 


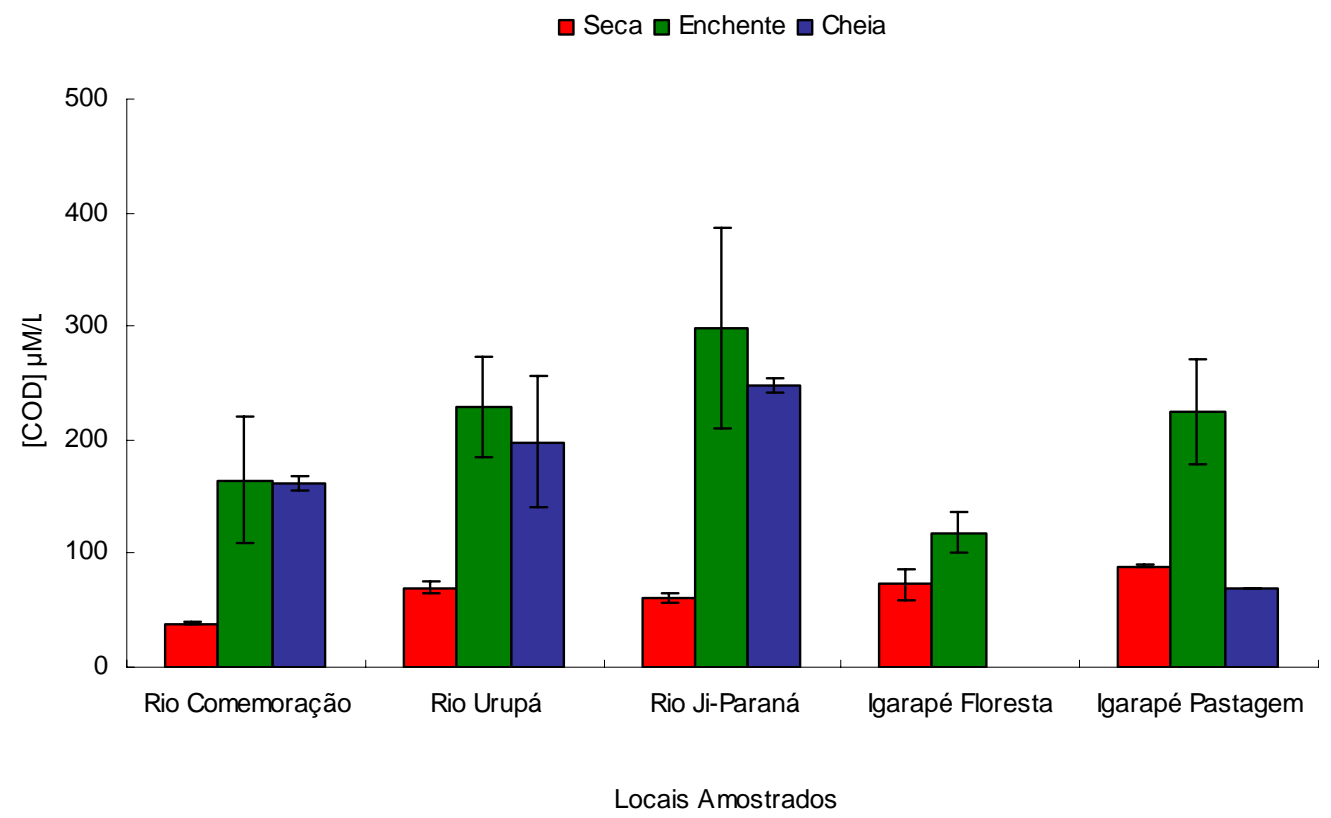

Figura 12 - Concentrações médias de carbono orgânico dissolvido nas águas dos rios amostrados neste estudo, em distintas épocas da hidrógrafa. Valores em $\mu \mathrm{M} / \mathrm{L}$

O aumento das concentrações de carbono orgânico dissolvido nos períodos de maiores vazões está relacionado com o aporte de material originado no ambiente terrestre e carreado para os sistemas fluviais pelo escoamento superficial, fato já observado por Leite (2004), em outros rios da bacia do Ji-Paraná, e McClain et al. (1997) em igarapés próximos a Manaus. Entretanto, o fato de, no igarapé da pastagem estas concentrações serem menores neste período pode indicar que também neste sistema houve alterações importantes nas vias de transporte da água. Resultados preliminares de um estudo em andamento na Pousada Rancho Grande (Cacaulândia, RO) estão indicando que a substituição da floresta por pastagem altera as vias de transporte da água (Gouveia Neto, com. pess.).

Nesta região similar à deste estudo, a conversão da floresta em pastagem provocou um aumento da compactação do solo e, a água da chuva, que infiltrava-se mais nos solos da floresta, passou a ter como via principal o escoamento sobre os mesmos. 
Desta forma, é possível que os resultados obtidos neste estudo indiquem que no período mais chuvoso esteja ocorrendo uma diluição deste carbono na água do canal pela água da chuva. Em outro estudo realizado na fazenda Nova Vida (Ariquemes, RO), resultados similares foram observados em relação às concentrações de COD, mas, neste caso, o aumento no período seco foi atribuído ao aporte de carbono proveniente de gramíneas que invadem o canal, mas não crescem sob a copa das árvores da floresta (Krusche, com. pess.). Ambas alternativas são possíveis no igarapé Boa Vista.

Na Figura 13 são apresentados os valores de $\mathrm{pH}$ das águas dos rios analisados neste estudo. Observa-se que os valores de $\mathrm{pH}$ variaram em torno de 6 a 7, próximos da neutralidade. Na enchente há uma tendência de diminuição destes valores, apesar de não ser estatisticamente significativa. Isto pode ser resultante do aporte relativamente maior do escoamento superficial, que ao percorrer a superfície dos solos carreia ácidos húmicos e fúlvicos, resultantes da decomposição da liteira (Perdue \& Gjessing, 1989). O rio Comemoração e o setor da pastagem do igarapé Boa Vista parecem não apresentar variações, ou então, um ligeiro aumento nestes valores.

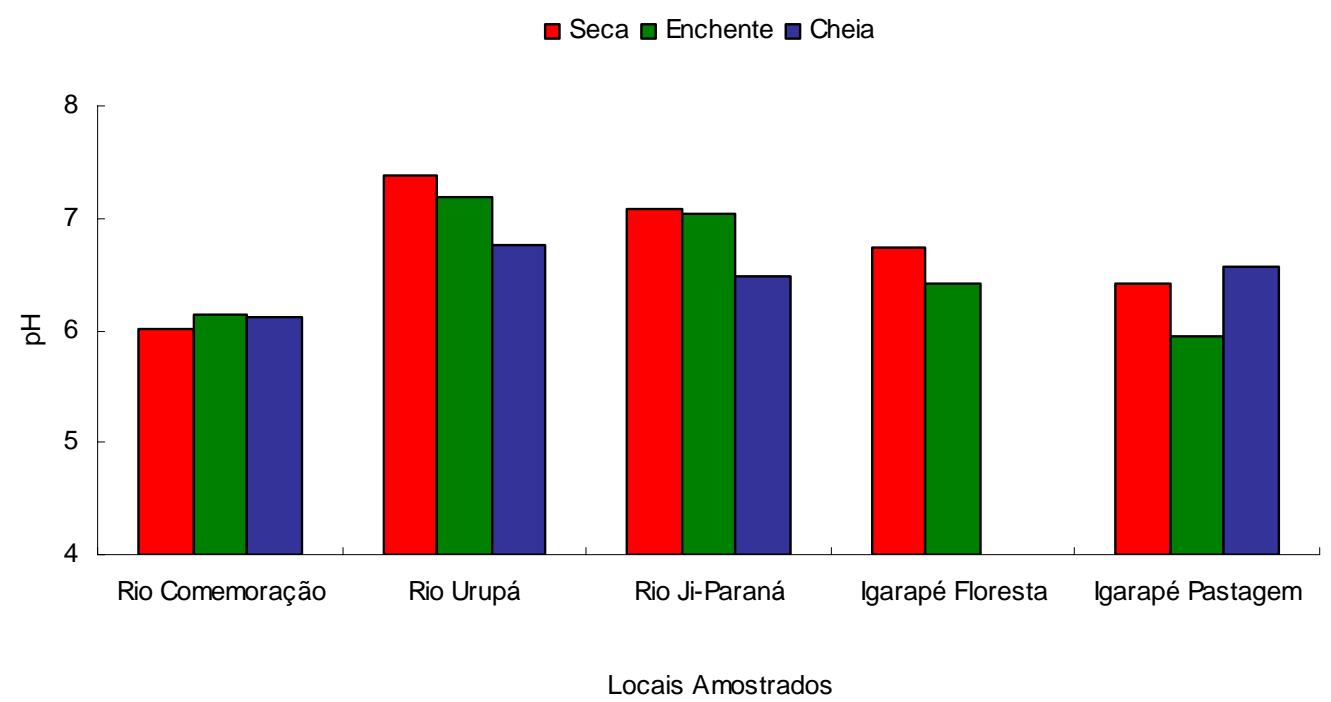

Figura 13 - Valores de pH das águas dos rios estudados, nos diferentes períodos amostrados 
Aparentemente, estas duas variáveis, carbono orgânico dissolvido e pH apresentam relação direta, o que pode indicar um papel relevante da primeira na definição da segunda, que poderia ser resultado de composição molecular. Sabe-se que a capacidade de tamponamento $(\mathrm{pH})$ de um sistema é de vital importância para a manutenção da vida. Quando o pH atinge valores extremos como 5,5 e 9,5 (muito ácidos ou muito básicos) podem ser alteradas a distribuição das comunidades aquáticas e a disponibilidade de carbono para o metabolismo destas (Wetzel, 1995).

\subsection{Experimentos de aumento das concentrações de Sedimentos em Suspensão Finos}

Nas Figuras 14 a 18, podem ser observadas as mudanças nas concentrações de carbono orgânico dissolvido nas amostras de água, imediatamente após a préconcentração das mesmas para testar os efeitos do aumento das concentrações de sedimentos em suspensão finos. Como esta fração do carbono existente na água é menor que o filtro utilizado $(0,1 \mu \mathrm{m})$, e o procedimento de ultrafiltração não altera a composição deste elemento, pode-se supor que esta pré-concentração favorece a dessorção do mesmo das partículas para a solução. Aufdenkampe et al. (2002) já haviam demonstrado que sedimentos de rios da Amazônia carreiam, adsorvidos a eles, diversos compostos orgânicos, como aminoácidos, por exemplo. Estes autores também demonstraram que tais compostos são facilmente dessorvidos do material particulado ao entrarem em contato com soluções aquosas mais diluídas em partículas.

Segundo Keil et al. (1994), a razão entre o carbono orgânico e a área superficial do sedimento (CO:AS) sugere que o carreamento da matéria orgânica possa ser controlado pela quantidade de área superficial disponível para adsorção, que é maior nos sedimentos finos, se comparados aos sedimentos grossos. Portanto, no caso dos experimentos com sedimentos em suspensão finos, discutidos a seguir, pode haver 
grande influência do carbono adsorvido aos mesmos, tendo em vista que este é o principal substrato para os processos respiratórios.

\section{Rio Comemoração}

O rio Comemoração drena solos que apresentam grandes concentrações de areia, e baixa saturação de bases. Em estudo realizado em uma toposequência na estação de Manejo Florestal ZF-2 do INPA, ao norte de Manaus (Neu, 2005), encontrou forte correlação entre as concentrações de carbono orgânico dissolvido (COD) na solução do solo com a textura do mesmo. Naquela área, nos latossolos localizados sob platô, e com os maiores teores de argila, foram encontradas as menores concentrações de COD na solução do solo, atribuídas à adsorção do mesmo às partículas de argila. No podzol, localizado no baixio, e com baixos teores de argila $(<15 \%)$, foram observados as maiores concentrações de carbono, disponibilizado à solução do solo em função da sua baixa capacidade de adsorção de COD. 


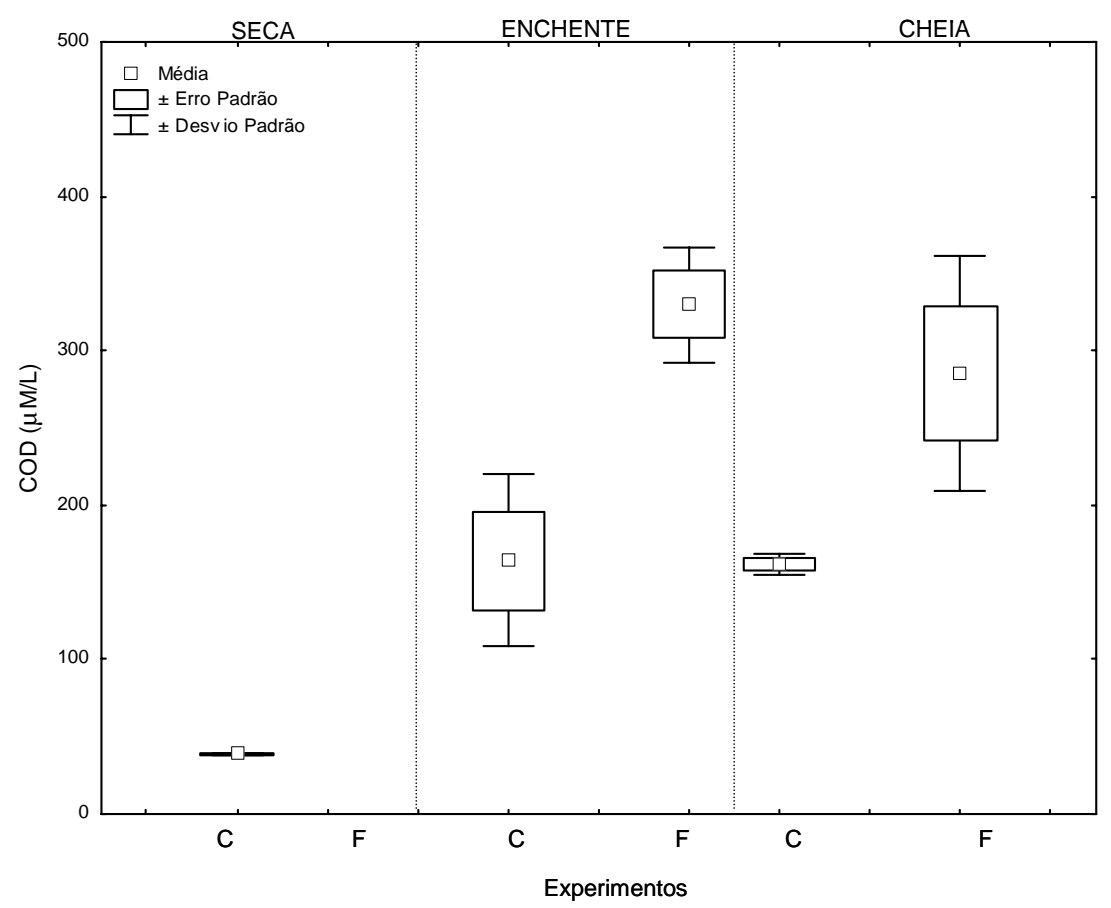

Figura 14 - Concentrações de carbono orgânico dissolvido (COD), nas amostras Controle (C) e enriquecidas com Sedimentos em Suspensão Finos (F), no rio Comemoração

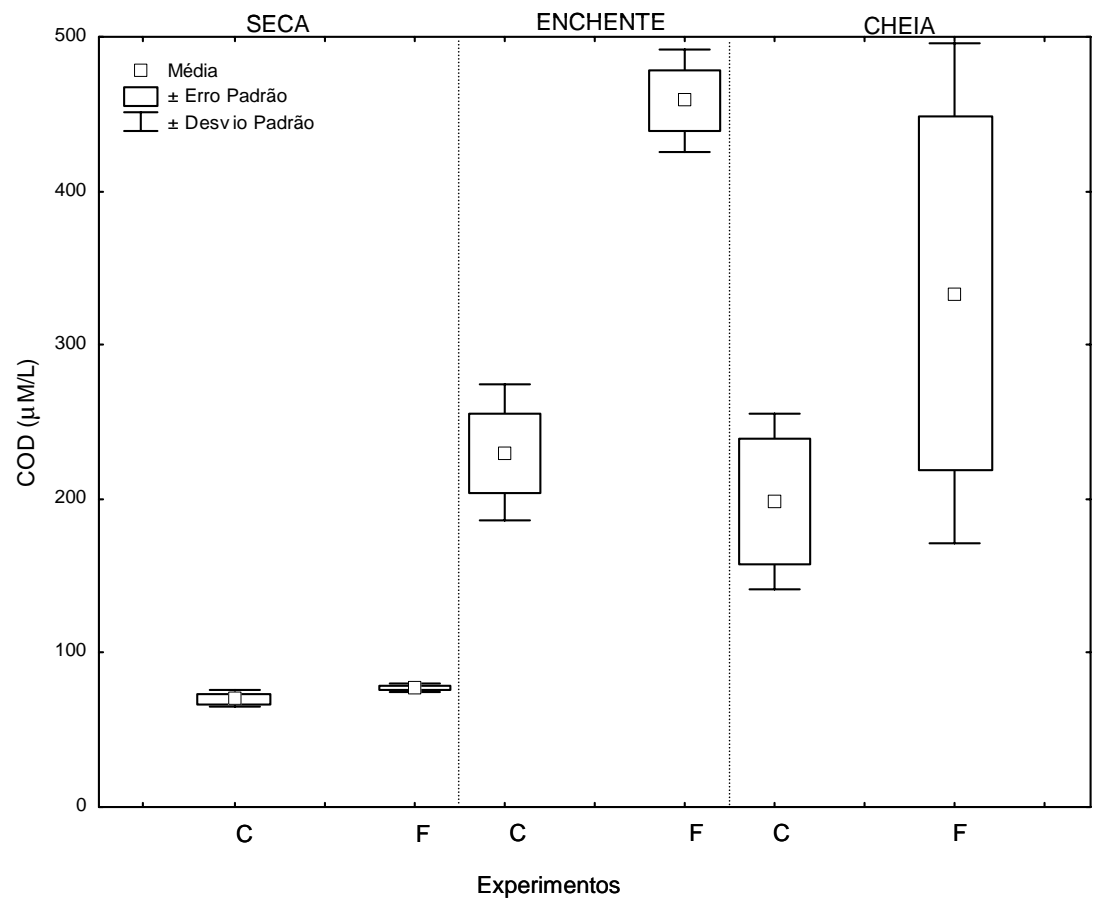

Figura 15 - Concentrações de carbono orgânico dissolvido (COD), nas amostras Controle (C) e enriquecidas com Sedimentos em Suspensão Finos (F), no rio Urupá 


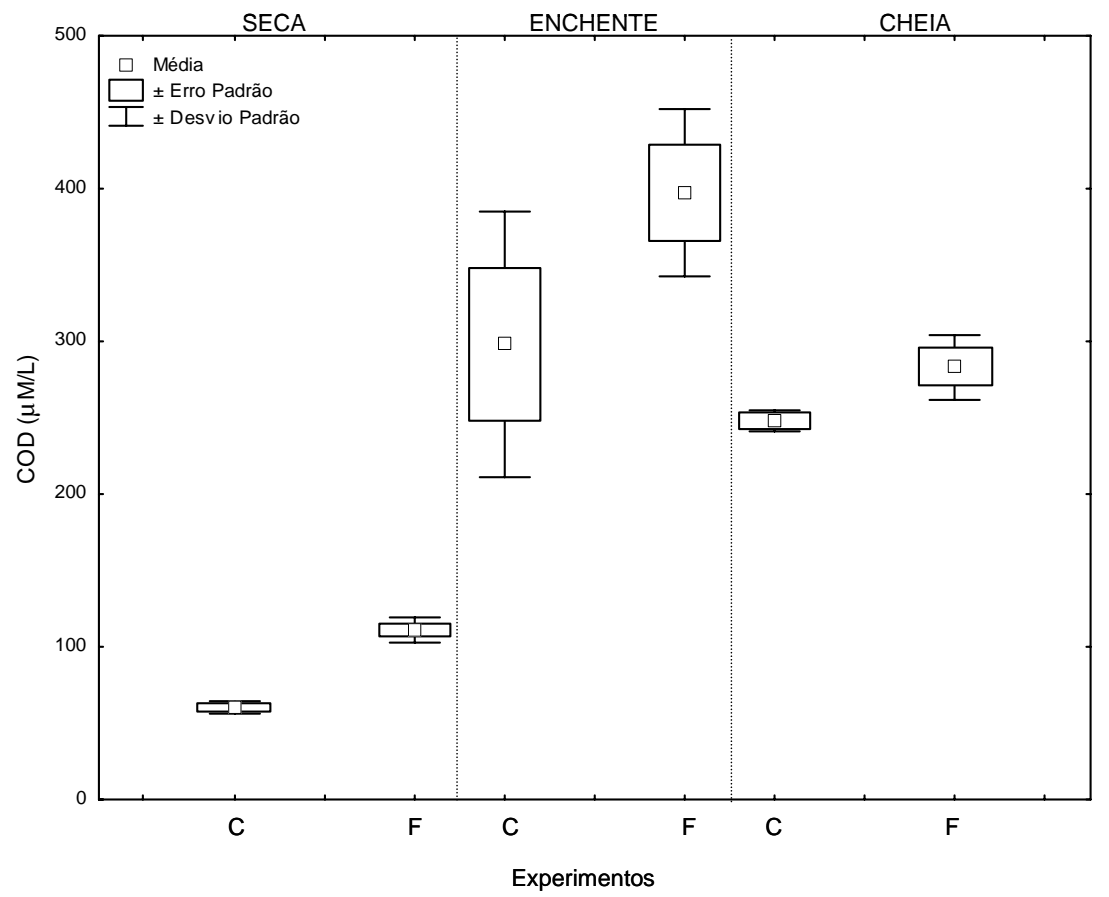

Figura 16 - Concentrações de carbono orgânico dissolvido (COD), nas amostras Controle (C) e enriquecidas com Sedimentos em Suspensão Finos (F), no rio Ji-Paraná

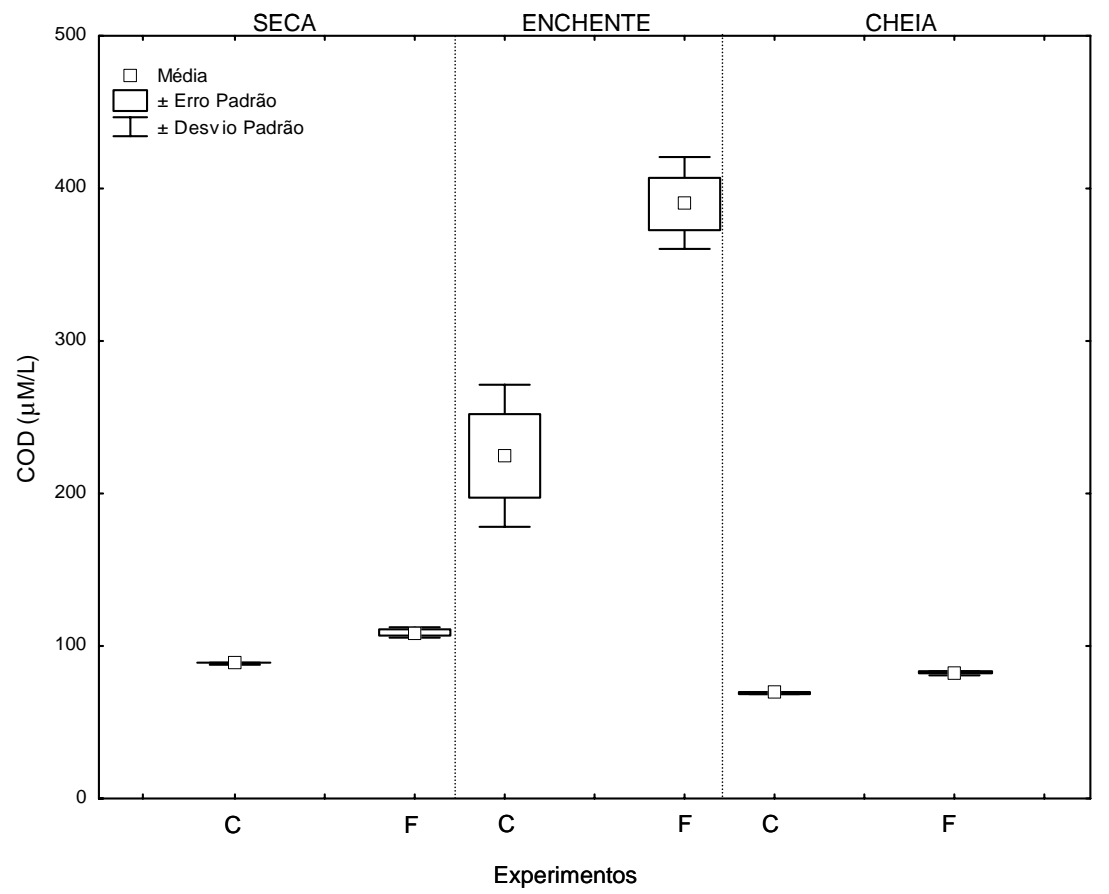

Figura 17 - Concentrações de carbono orgânico dissolvido (COD), nas amostras Controle (C) e enriquecidas com Sedimentos em Suspensão Finos (F), no Igarapé Boa Vista, no trecho da Pastagem 


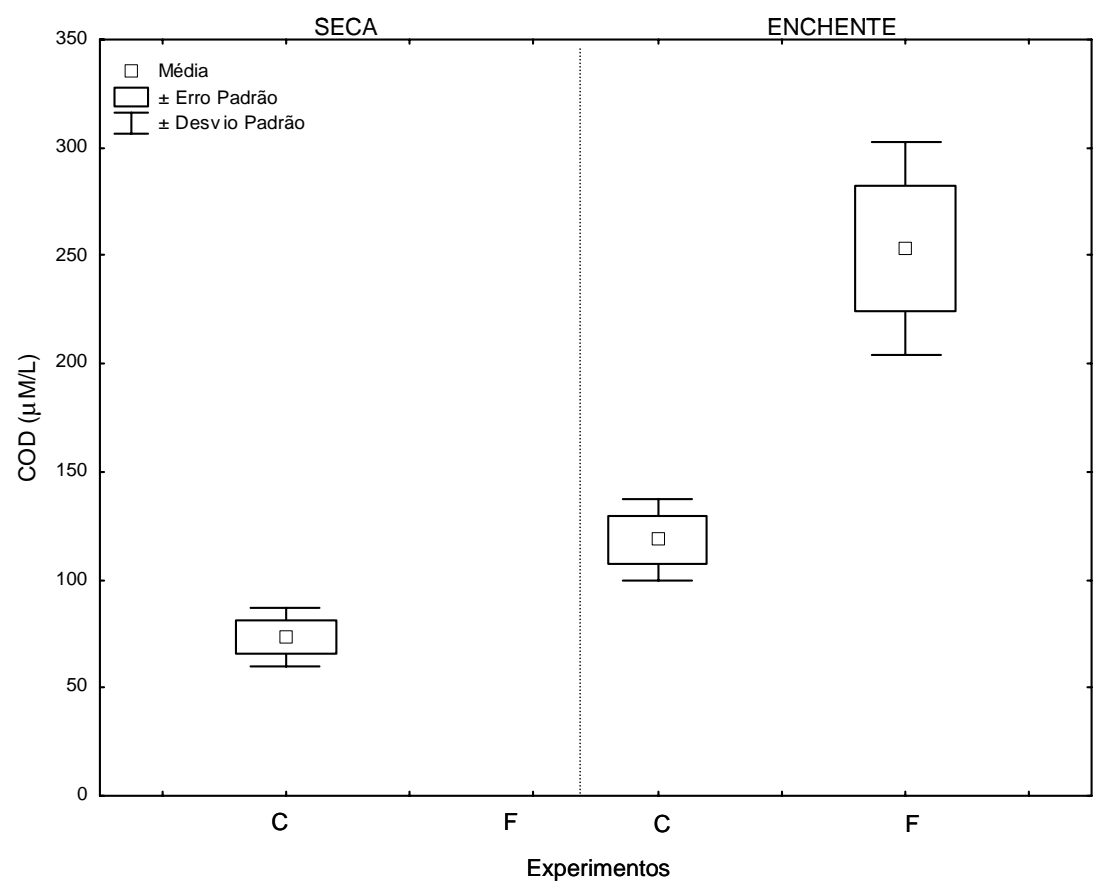

Figura 18 - Concentrações de carbono orgânico dissolvido (COD), nas amostras Controle (C) e enriquecidas com Sedimentos em Suspensão Finos (F), no Igarapé Boa Vista, no trecho da Floresta

Portanto, seria esperado que, apesar das concentrações de carbono orgânico dissolvido pudessem ser maiores nas águas de percolação, os sedimentos carreados pelas chuvas nesta bacia tendem a ser mais arenosos e conter menores quantidades de COD adsorvido a eles. De fato, em comparação com as variações nas concentrações de COD antes e após a pré-concentração, observadas no rio Urupá (que tem os solos mais argilosos da bacia do rio Ji-Paraná, ver adiante), nas águas do rio Comemoração estes sedimentos são menos ricos em carbono orgânico. Este fato pode estar associado também às diferenças observadas nas variações nas taxas respiratórias, pois o aumento destas após a adição destes sedimentos foi menor no rio Comemoração, em comparação com o rio Urupá, por exemplo.

Na Figura 19 são apresentadas as variações nas taxas respiratórias no rio Comemoração, após a concentração dos sedimentos em suspensão finos. No período de seca, a concentração destes sedimentos não produziu elevações estatisticamente 
significativas nas taxas respiratórias, que variaram de $0,61 \mu \mathrm{M} \cdot \mathrm{h}^{-1}$ a $0,69 \mu \mathrm{M} \cdot \mathrm{h}^{-1}$ após incubação por 24 horas (com coeficiente de correlação entre aumento da concentração de sedimentos e aumento das taxas respiratórias, $\mathrm{r}^{2}$, de 0,29 e uma probabilidade de erro, p, de 0,46$)$ e de $0,62 \mu \mathrm{M} . \mathrm{h}^{-1}$ para $0,64 \mu \mathrm{M} \cdot \mathrm{h}^{-1}$ após incubação por 48 horas $\left(\mathrm{r}^{2}=0,23\right.$ e $\mathrm{p}$ = 0,52). Apesar das concentrações de carbono orgânico dissolvido não terem sido determinadas nestas duas incubações específicas, os resultados obtidos nos outros experimentos indicam que estes sedimentos, neste período do ano, possuem menores quantidades deste substrato da respiração. Portanto, é possível que a falta de substrato neste caso seja o responsável pelas alterações não significativas do metabolismo deste rio, em função do aumento das concentrações de sedimentos.

Nos períodos de enchente e cheia, os resultados foram bastante distintos, com aumentos estatisticamente significativos nas taxas respiratórias após a pré-concentração de sedimentos. Na enchente, as taxas respiratórias variaram de $0,13 \mu \mathrm{M} \cdot \mathrm{h}^{-1}$ a $1,19 \mu \mathrm{M} \cdot \mathrm{h}^{-}$ ${ }^{1}$ após 24 horas de incubação $\left(r^{2}=0,98\right.$ e p =0,01), e de 0,22 $\mu \mathrm{M} \cdot \mathrm{h}^{-1}$ a 1,07 $\mu \mathrm{M} \cdot \mathrm{h}^{-1}$ após 48 horas de incubação $\left(r^{2}=0,95\right.$ e $\left.\mathrm{p}=0,03\right)$. Na cheia, as incubações por 24 horas não produziram alterações estatisticamente significativas nas taxas respiratórias, que variaram de $0,27 \mu \mathrm{M} \cdot \mathrm{h}^{-1}$ a $0,26 \mu \mathrm{M} \cdot \mathrm{h}^{-1}\left(\mathrm{r}^{2}=0,0043\right.$ e $\left.\mathrm{p}=0,93\right)$. Porém, após 48 horas de incubação também foram observadas variações significativas, com valores aumentando de $0,47 \mu . h^{-1}$ para $1,11 \mu \mathrm{M} \cdot \mathrm{h}^{-1}\left(\mathrm{r}^{2}=0,97\right.$ e $\left.\mathrm{p}=0,02\right)$.

O fato das incubações por 24 horas, no período de cheia, neste ponto, não produzirem respostas significativas nas taxas respiratórias pode ser um indício de que, não somente as concentrações de substrato (matéria orgânica) para a respiração, mas também a qualidade deste, podem ser importantes mecanismos de controle do metabolismo. É possível que, apesar do fator de aumento nas concentrações de carbono orgânico nas águas deste rio, após o processo de pré-concentração, ser similar para os 


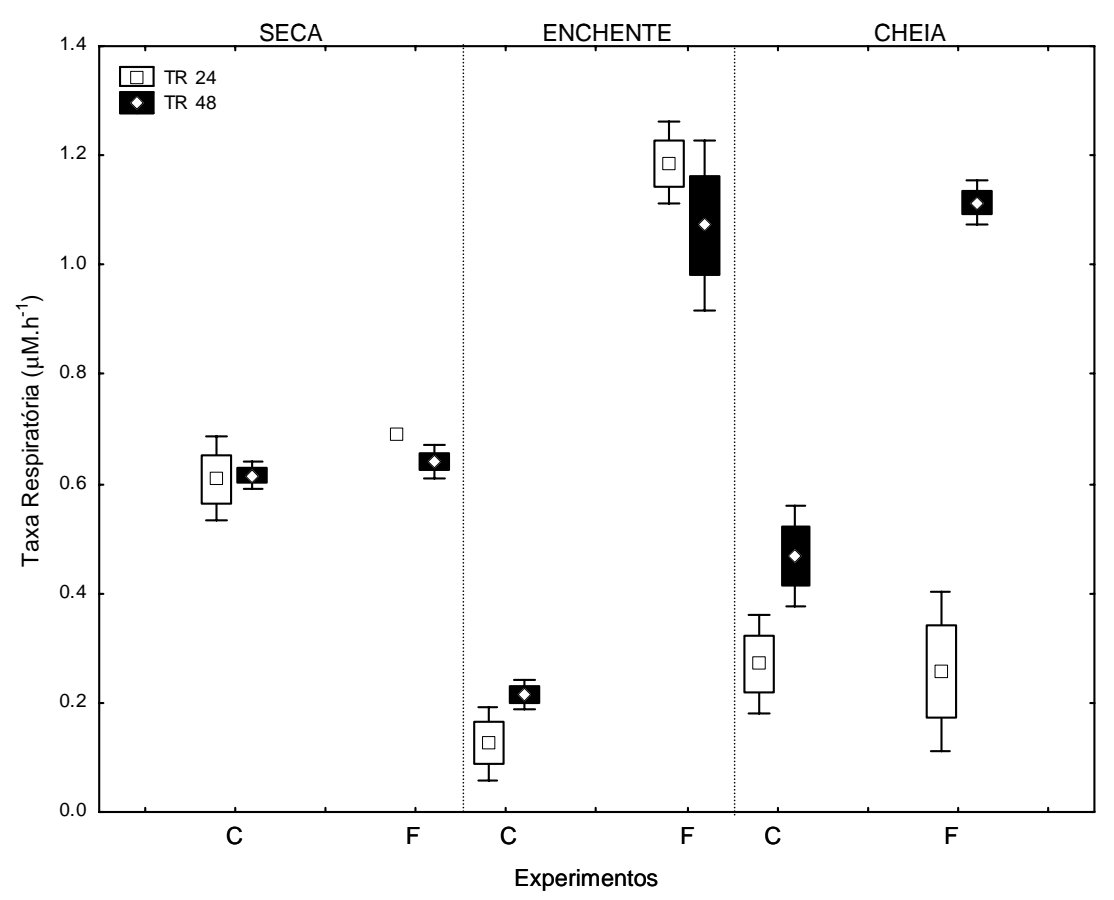

Figura 19 - Variação das taxas respiratórias no rio Comemoração, após 24 e 48 horas de incubação dos experimentos Controle (C) e enriquecidos com Sedimentos em Suspensão Finos (F). Valores em $\mu M \cdot h^{-1}$

dois períodos, sua composição seja distinta. O carbono orgânico dissolvido presente nas amostras deste rio pode ter características mais refratárias no período de cheia, exigindo maior tempo para ser metabolizado. Como será discutido a seguir, resultados similares foram observados em alguns dos outros rios estudados. Tais resultados são coerentes com o esperado para o ciclo do carbono em rios, no qual as primeiras chuvas podem ser responsáveis pela maior parte do transporte do elemento dos ambientes terrestres para os aquáticos (Depetris \& Paolini, 1991) 


\section{Rio Urupá}

O rio Urupá está localizado na área mais fértil da bacia, drenando solos argilosos ou muito argilosos, com alta saturação de bases e solos menos intemperizados. Portanto, seria esperado que os sedimentos em suspensão finos nas suas águas apresentassem concentrações relativamente maiores de carbono orgânico dissolvido adsorvido aos mesmos, em relação aquelas observadas no rio Comemoração. De fato, ao comparar-se as Figuras 14 e 15, percebe-se que, não somente as concentrações iniciais, como também os fatores de concentração do COD são maiores neste rio.

As respostas nas taxas respiratórias, observadas nas amostras do rio Urupá, após o incremento das concentrações de sedimentos em suspensão finos, podem ser vistas na Figura 20. Na seca, as taxas respiratórias aumentaram de $0,81 \mu \mathrm{M} . \mathrm{h}^{-1}$ para 1,23 $\mu \mathrm{M} . \mathrm{h}^{-1}$, após 24 horas de incubação, e de $0,65 \mu \mathrm{M} \cdot \mathrm{h}^{-1}$ para $0,95 \mu \mathrm{M} \cdot \mathrm{h}^{-1}$ após 48 horas de incubação. Estas elevações nas taxas respiratórias se correlacionam de maneira estatisticamente significativa à elevação nas concentrações de sedimentos, pois apresentaram $\mathrm{r}^{2}=0,99$ e $\mathrm{p}=0,01$, e $\mathrm{r}^{2}=0,93$ e $\mathrm{p}=0,04$, respectivamente. 


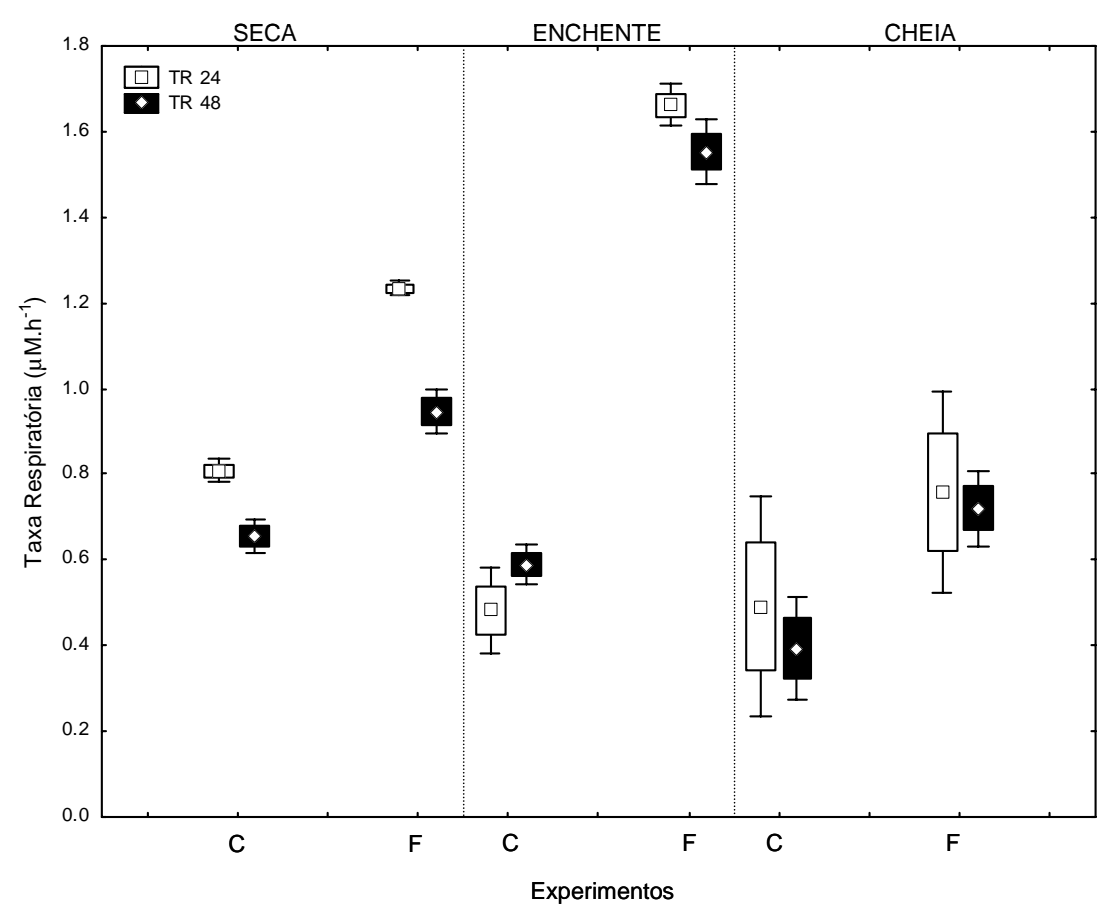

Figura 20 - Variações das taxas respiratórias no rio Urupá, após 24 e 48 horas de incubação dos experimentos Controle (C) e enriquecidos com Sedimentos em Suspensão Finos (F). Valores em $\mu \mathrm{M} \cdot \mathrm{h}^{-1}$

Assim como observado no rio Comemoração, no período de enchente, a concentração de sedimentos em suspensão finos provocou os maiores aumentos nas taxas respiratórias deste rio. Nas incubações de 24 horas as taxas aumentaram de 0,48 $\mu \mathrm{M} . \mathrm{h}^{-1}$ para $1,66 \mu \mathrm{M} \cdot \mathrm{h}^{-1}\left(\mathrm{r}^{2}=0,98\right.$ e $\left.\mathrm{p}=0,01\right)$, ao passo que após 48 horas este aumento foi de $0,59 \mu \mathrm{M} \cdot \mathrm{h}^{-1}$ para $1,55 \mu \mathrm{M} \cdot \mathrm{h}^{-1}\left(\mathrm{r}^{2}=0,98\right.$ e $\left.\mathrm{p}=0,01\right)$. No período de cheia, apesar de haver aumento nas taxas respiratórias com o aumento das concentrações de sedimentos, não foram observadas relações estatisticamente significativas. Nesta época as taxas respiratórias variaram de $0,49 \mu \mathrm{M} \cdot \mathrm{h}^{-1}$ a $0,76 \mathrm{uM} \cdot \mathrm{h}^{-1}$, após incubação por 24 horas $\left(\mathrm{r}^{2}=0,30\right.$ e $\left.\mathrm{p}=0,45\right)$, e de $0,39 \mu \mathrm{M} \cdot \mathrm{h}^{-1}$ para $0,72 \mu \mathrm{M} \cdot \mathrm{h}^{-1}$ após incubação por 48 horas $\left(r^{2}=0,78\right.$ e $\left.\mathrm{p}=0,12\right)$. Novamente, estes resultados indicam o transporte, na fração fina dos sedimentos, de uma matéria orgânica mais lábil no período da enchente, seguido 
do período de cheia e, com o período de seca apresentando o material relativamente mais refratário adsorvido aos sedimentos ao longo do ano.

\section{Rio Ji-Paraná}

Na Figura 21 podem ser vistas as variações das taxas respiratórias nas águas do rio Ji-Paraná, em função do aumento da concentração dos sedimentos em suspensão finos. Na seca, as taxas variaram de $0,39 \mu \mathrm{M}^{-1}{ }^{-1}$ a $1 \mu \mathrm{M} \cdot \mathrm{h}^{-1}$ após incubação por 24 horas $\left(r^{2}=0,98\right.$ e p $\left.=0,01\right)$, e de $0,44 \mu \mathrm{M} \cdot \mathrm{h}^{-1}$ a $0,96 \mu \mathrm{M} \cdot \mathrm{h}^{-1}$ após 48 horas de incubação $\left(\mathrm{r}^{2}=\right.$ $0,93$ e p $=0,04)$. No período de enchente, estes aumentos foram superiores, com as taxas respiratórias variando de 0,40 $\mu \mathrm{M} . \mathrm{h}-1$ a 1,21 $\mu \mathrm{M} . \mathrm{h}^{-1}$ nas incubações por 24 horas e de

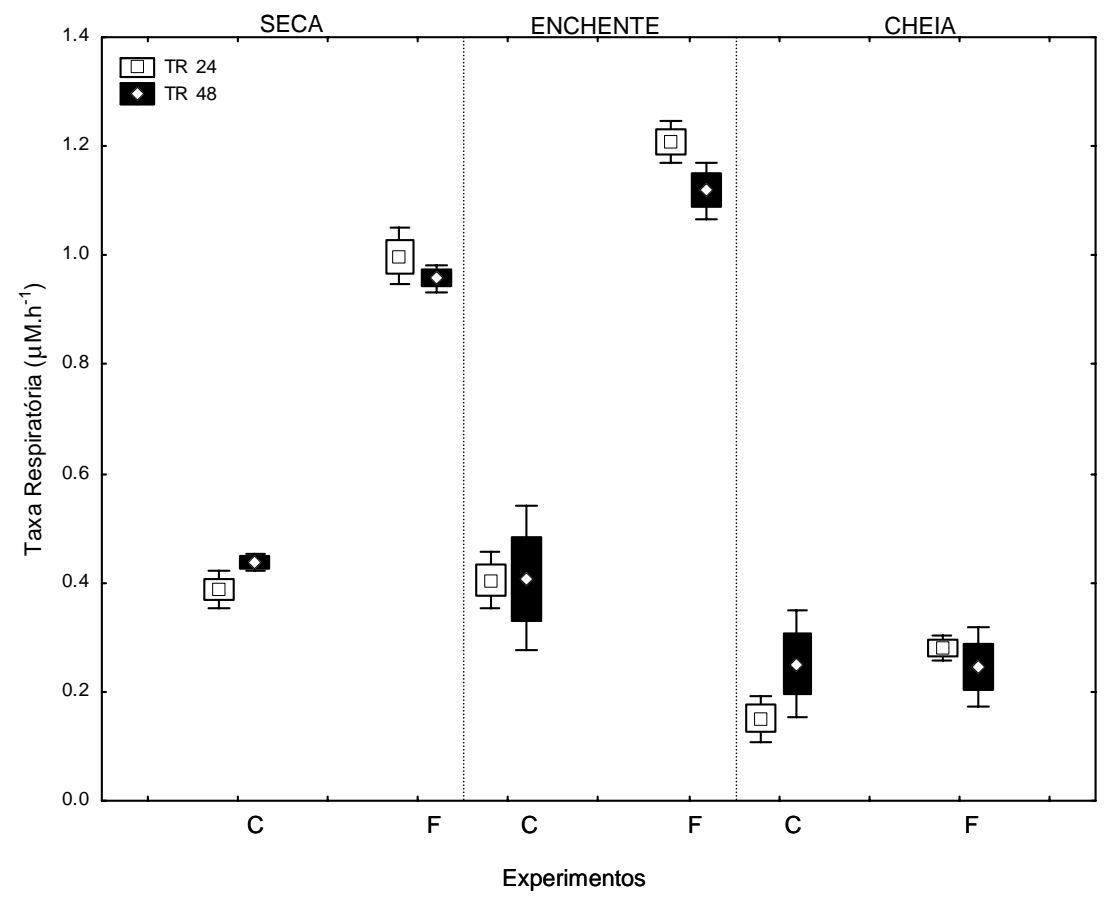

Figura 21 - Variações das taxas respiratórias no rio Ji-Paraná, após 24 e 48 horas de incubação dos experimentos Controle (C) e enriquecidos com Sedimentos em Suspensão Finos (F). Valores em $\mu M^{-1}{ }^{-1}$ 
$0,41 \mu \mathrm{M} \cdot \mathrm{h}^{-1}$ a $1,12 \mu \mathrm{M} \cdot \mathrm{h}^{-1}\left(\mathrm{r}^{2}=0,94\right.$ e $\mathrm{p}=0,03$,), após incubação por 48 horas. No período de cheia, o aumento das taxas respiratórias, de $0,15 \mu \mathrm{M} \cdot \mathrm{h}^{-1}$ para $0,28 \mu \mathrm{M} . \mathrm{h}^{-1}$ após incubação por 24 horas apresentou correlação positiva e estatisticamente significativa com o incremento das concentrações de sedimentos em suspensão finos $\left(\mathrm{r}^{2}\right.$ $=0,83$ e p =0,09), mas nas incubações por 48 horas não houve alterações significativas, com valores de $0,25 \mu \mathrm{M} . \mathrm{h}^{-1}$ no controle e de 0,24 $\mu \mathrm{M} \cdot \mathrm{h}^{-1}$ após a incubação $\left(\mathrm{r}^{2}=0,0023\right.$ e $\mathrm{p}=0,95)$.

Em termos da composição dos solos da sua bacia de drenagem e, consequentemente, das características dos sedimentos em suspensão carreados pelo rio, o rio Ji-Paraná pode ser considerado como um intermediário entre os rios Comemoração e Urupá. Enquanto na bacia de drenagem do primeiro ocorrem solos mais arenosos e na do segundo solos mais argilos, o ponto amostrado do rio Ji-Paraná drena uma área cuja composição dos solos é de aproximadamente 50\% de cada um destes tipos. Isto explicaria o fato dos resultados obtidos neste rio, em termos dos fatores de aumento das taxas respiratórias com a pré-concentração de sedimentos em suspensão finos, se encontrarem, em termo gerais, em patamares intermediários.

Entretanto, em relação à qualidade do material orgânico respirado, nos 3 casos citados há respostas bastante distintas no período de cheia. Enquanto no rio Urupá há aumento da respiração tanto após 24 horas de incubação quanto após 48 horas, no rio Comemoração os aumentos somente ocorrem após 48 horas e, no rio Ji-Paraná somente após 24 horas. Isto parece indicar que o substrato mais lábil, disponível para a respiração no rio Ji-Paraná, não é suficiente para manter o metabolismo microbiano por períodos mais longos, sendo rapidamente consumido. Apesar deste metabolismo depender também de outros nutrientes, como nitrogênio e fósforo, e variar em função de inúmeras outras variáveis, como temperatura, por exemplo, neste estudo não é possível determinar a importância relativa de cada um de todos os fatores controladores no metabolismo aquático destes rios. 


\section{Igarapé Boa Vista Pastagem}

No setor da pastagem do Igarapé Boa Vista, os resultados da concentração dos sedimentos em suspensão finos nas taxas respiratórias foram similares aos outros rios para o período de seca e de enchente, com variações estatisticamente significativas em ambas. Na seca, as taxas respiratórias aumentaram de $0,12 \mu \mathrm{M} \cdot \mathrm{h}^{-1}$ para $0,33 \mu \mathrm{M} \cdot \mathrm{h}^{-1}\left(\mathrm{r}^{2}=\right.$ 0,98 e p = 0,01), nas incubações por 24 horas (Figura 22). Nas incubações por 48 horas, as taxas respiratórias passaram de $0,34 \mu \mathrm{M} . \mathrm{h}^{-1}$ nas garrafas controle para $0,52 \mu \mathrm{M} . \mathrm{h}^{-1}$ nas garrafas enriquecidas em sedimentos $\left(\mathrm{r}^{2}=0,99\right.$ e $\left.\mathrm{p}=0,01\right)$. No período de enchente, a elevação nas taxas respiratórias foi de $0,32 \mu \mathrm{M} . \mathrm{h}^{-1}$ para 1,46 $\mu \mathrm{M} \cdot \mathrm{h}^{-1}$ após 24 horas de incubação $\left(\mathrm{r}^{2}=0,98\right.$ e $\left.\mathrm{p}=0,01\right)$, e de $0,30 \mu \mathrm{M} \cdot \mathrm{h}^{-1}$ para $1,38 \mu \mathrm{M} \cdot \mathrm{h}^{-1}$, após 48 horas $\left(\mathrm{r}^{2}=\right.$ $0,99$ e $\mathrm{p}=0,01)$. Porém, na cheia, o incremento das concentrações de sedimentos em suspensão finos provocou reduções nas taxas respiratórias, que passaram de $0,20 \mu \mathrm{M}^{-1} \mathrm{~h}^{-1}$ a $0,04 \mu \mathrm{M} \cdot \mathrm{h}^{-1}$ nas incubações por 24 horas $\left(\mathrm{r}^{2}=0,04\right.$ e $\left.\mathrm{p}=0,80\right)$, e de $0,26 \mu \mathrm{M} \cdot \mathrm{h}^{-1}$ para aproximadamente zero nas incubações por 48 horas $\left(r^{2}=0,81\right.$ e $\left.\mathrm{p}=0,10\right)$.

Tais resultados para o período de cheia são supreendentes, mas podem estar relacionados com o aumento não significativo nas concentrações de carbono orgânico dissolvido (ver Figura 17), observado neste experimento.

As mudanças observadas na paisagem na bacia do rio Ji-Paraná, nos quais a cobertura vegetal de floresta passa a ser totalmente rasteira, composta quase que exclusivamente por gramíneas, tem como principal conseqüência à eliminação da limitação da produtividade primária.

Isso permite o desenvolvimento, nos igarapés de pastagem, uma vegetação ripária inexistente na floresta, composta quase que exclusivamente por capim Paspalum. Este capim invade o canal e constitui-se em um aumento extra de matéria orgânica que modifica completamente a biogeoquímica destes sistemas tão frágeis. Os processos respiratórios e de decomposição desta gramínea são suficientes para alterar totalmente o metabolismo destes igarapés. 
Estudos realizados em igarapés da Nova Vida evidenciam que estas alterações favorecem a conversão de um sistema aeróbio para anaeróbio, como conseqüência das mudanças na cobertura e uso da terra (Krusche et al., artigo não publicado). Evidências adicionais destas mudanças são o aumento das concentrações de Carbono Orgânico (COD) e inorgânico (CID) Dissolvidos na pastagem, em relação às concentrações observadas na floresta.

Segundo este mesmo estudo, o aumento da produtividade primária por fitoplâncton e perifíton não é significativamente maior na pastagem (dados não publicados), pode-se atribuir o aumento das concentrações de COD à invasão das regiões ripárias e do canal, na pastagem, por Paspalum. Esta fonte extra de carbono e o metabolismo destas plantas é suficiente para consumir a maior parte do oxigênio dissolvido nestas águas e aumentar as concentrações de carbono inorgânico dissolvido, indicando tratar-se de material bastante lábil.

É possível observar após o processo de enriquecimento das amostras com Sedimento em Suspensão Fino (SSF), que as concentrações de COD são elevadas significativamente (Figura 17); e se comparadas às concentrações do mesmo igarapé na floresta, estas concentrações são superiores (mostrados a diante).

Na seca, a concentração de COD que fora de $89 \mu \mathrm{M} / \mathrm{L}$ nos experimentos controle passou para $\sim 110 \mu \mathrm{M} / \mathrm{L}$ após o processo de pré-concentração das amostras. Este aumento também pode ser relacionado às elevações nas taxas respiratórias de $0,12 \mu \mathrm{M} \cdot \mathrm{h}^{-}$ 1 nas garrafas controle para $0,33 \mu \mathrm{M} \cdot \mathrm{h}^{-1}$ após enriquecimento com Sedimento em Suspensão Fino (SSF). Estas elevações foram correlacionadas ao aumento nas concentrações de sedimentos pois apresentaram $r^{2}=0,98$ e $p=0,01$, para as incubações por 24 horas (Figura 22). Nas incubações por 48 horas, as taxas respiratórias passaram de $0,34 \mu \mathrm{M} \cdot \mathrm{h}^{-1}$ nas garrafas controle para $0,52 \mu \mathrm{M} \cdot \mathrm{h}^{-1}$ nas garrafas enriquecidas $\left(\mathrm{r}^{2}=\right.$ 0,99 e $\mathrm{p}=0,01$ ), portanto, ambos os aumentos nas taxas observados foram relacionadas às elevações nas concentrações de sedimentos, corroborando com o aumento também das concentrações de COD. 


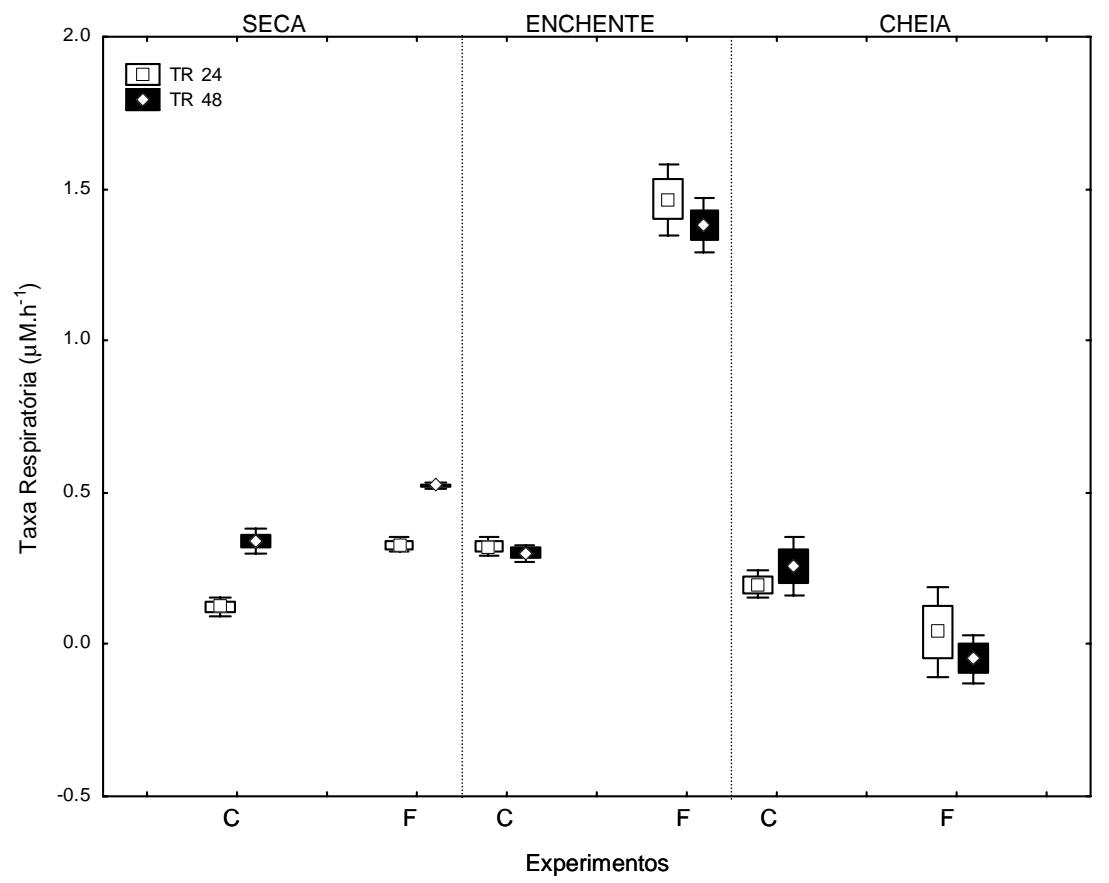

Figura 22 - Variação das taxas respiratórias no Igarapé Boa Vista Pastagem, após 24 e 48 horas de incubação dos experimentos Controle (C) e enriquecidos com Sedimento em Suspensão Fino (F). Valores em $\mu M \cdot h^{-1}$

No período de enchente, a elevação observada nas taxas respiratórias fora em decorrência das elevações nas concentrações de COD favorecidas pelo enriquecimento das amostras com sedimentos, Figura 22.

$\mathrm{Na}$ cheia, as reduções observadas possivelmente correlacionam-se com a disponibilidade de carbono para o sistema, dado que a concentração de COD após o enriquecimento passou de $70 \mu \mathrm{M} / \mathrm{L}$ para $83 \mu \mathrm{M} / \mathrm{L}$. Talvez este carbono adicional apresente uma razão $\mathrm{C}: \mathrm{N}$ baixa, sendo mais refratário devido à sua constituição, que é quase que exclusivamente por folhas não decompostas, as quais apresentam uma concentração maior de nitrogênio. 


\section{Igarapé Boa Vista Floresta}

Para o período de seca, no Igarapé Boa Vista Floresta, o enriquecimento das amostras com Sedimento em Suspensão Fino (SSF) favoreceu redução nas taxas respiratórias. Nas incubações por 24 horas, a taxa respiratória passou de $0,61 \mu \mathrm{M} \cdot \mathrm{h}^{-1}$ no controle para 0,46 $\mu \mathrm{M} \cdot \mathrm{h}^{-1}$ nas garrafas enriquecidas com SSF, com $\mathrm{r}^{2}=0,42$ e $\mathrm{p}=0,35$. Para o mesmo período, as incubações por 48 horas corroboraram em pequenas reduções, de $0,45 \mu \mathrm{M} \cdot \mathrm{h}^{-1}$ nas garrafas controle para $0,43 \mu \mathrm{M} \cdot \mathrm{h}^{-1}$ nas garrafas enriquecidas com $\operatorname{SSF}\left(r^{2}=0,04\right.$ e $\left.p=0,80\right)$, Figura 23.

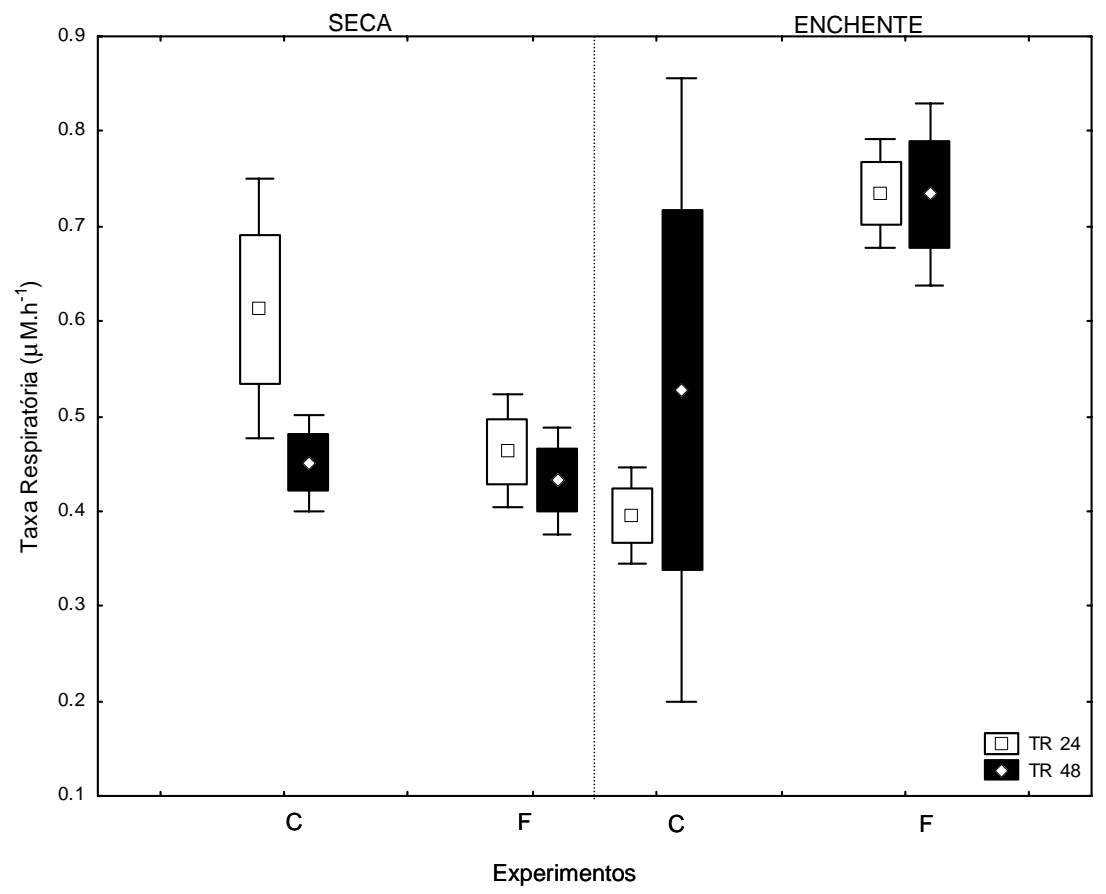

Figura 23 - Variação das taxas respiratórias no Igarapé Boa Vista Floresta, após 24 e 48 horas de incubação dos experimentos Controle (C) e enriquecidos com Sedimento em Suspensão Fino (F). Valores em $\mu M \cdot h^{-1}$ 
Contudo, as reduções observadas não foram correlacionadas com o aumento nas concentrações de sedimentos, mas possivelmente com as concentrações de COD (Figura 18). Por falhas no procedimento de amostragem, as alíquotas necessárias para a quantificação das concentrações de COD não foram retiradas, impossibilitando afirmações quanto a relações nas alterações das taxas respiratórias.

$\mathrm{Na}$ enchente, como pode ser observado na Figura 23, o enriquecimento das amostras com SSF elevou significativamente as taxas respiratórias. Para as incubações por 24 horas, as taxas respiratórias passaram de $0,40 \mu \mathrm{M} . \mathrm{h}^{-1}$ no controle para $0,73 \mathrm{uM} \cdot \mathrm{h}^{-}$

${ }^{1}$, com $\mathrm{r}^{2}=0,93$ e $\mathrm{p}=0,04$. Nas incubações por 48 horas, a mesma tendência pode ser observada, nas garrafas controle a taxa respiratória fora de $0,53 \mu \mathrm{M} \cdot \mathrm{h}^{-1}$ passando para $0,73 \mu \mathrm{M} \cdot \mathrm{h}^{-1}\left(\mathrm{r}^{2}=0,21\right.$ e $\left.\mathrm{p}=0,54\right)$. Portanto, as elevações observadas para este período provavelmente estão relacionadas ao aumento nas concentrações de sedimentos, que favorece o aumento nas concentrações de COD nas amostras enriquecidas.

\subsection{Experimentos com adição de concentrados de Sedimentos em Suspensão Grossos}

As incubações no escuro das amostras de água dos rios, após a adição de concentrados de sedimentos em suspensão grossos, reforçam algumas das hipóteses sugeridas para explicar o observado nas amostras que tiveram as concentrações de sedimentos em suspensão finos concentradas antes de serem incubadas. Em geral, nestes experimentos, observou-se que, no período seco, a adição deste material mais grosso não acarreta em mudanças estatisticamente significativas nas taxas respiratórias. Isto está de acordo com os resultados de Keil et al. (1997) e Aufdenkampe et al. (2001), a cerca do papel relativo destas duas frações de sedimento na ciclagem de substâncias orgânicas em rios.

Como a área disponível para adsorção é, em comparação com os sedimentos em suspensão finos, relativamente menor nos grossos, a quantidade de compostos orgânicos 
carreados adsorvidos pelos mesmos também é menor. Desta forma, nos períodos em que o escoamento superficial é constituído essencialmente pelo fluxo de base, esta fração da carga de sedimentos tem características mais minerais e seu papel como substrato para processos respiratórios é insignificante. Entretanto, com o aumento da precipitação nos períodos chuvosos, passam a ser importantes os aportes do ambiente terrestre pelas vias de transporte sobre os solos. Apesar de não quantificado neste estudo, sabe-se que as enxurradas são responsáveis pelo arraste de grandes quantidades de solo e da serrapilheira dos ambientes terrestres para os aquáticos. Assim, nos períodos de enchentes e cheia, uma fração maior, em relação ao período de seca, dos sedimentos em suspensão grossos é constituída de detritos orgânicos, que podem servir de substrato para a respiração.

\section{Rio Comemoração}

No rio Comemoração, no período de seca, a adição de concentrados de sedimentos em suspensão grossos às amostras da água do rio provocou uma diminuição, ainda que não estatisticamente significativa, nas taxas respiratórias, tanto após 24 horas, quanto após 48 horas de incubação (Figura 24). No primeiro intervalo de tempo, as taxas

respiratórias oscilaram de 0,61 $\mu \mathrm{M} \cdot \mathrm{h}^{-1}$ a $0,46 \mu \mathrm{M} \cdot \mathrm{h}^{-1}\left(\mathrm{r}^{2}=0,54\right.$ e p = 0,27), enquanto no segundo estas variações foram de $0,62 \mu \mathrm{M} \cdot \mathrm{h}^{-1}$ a $0,53 \mu \mathrm{M} \cdot \mathrm{h}^{-1}\left(\mathrm{r}^{2}=0,58\right.$ e p = 0,24). 


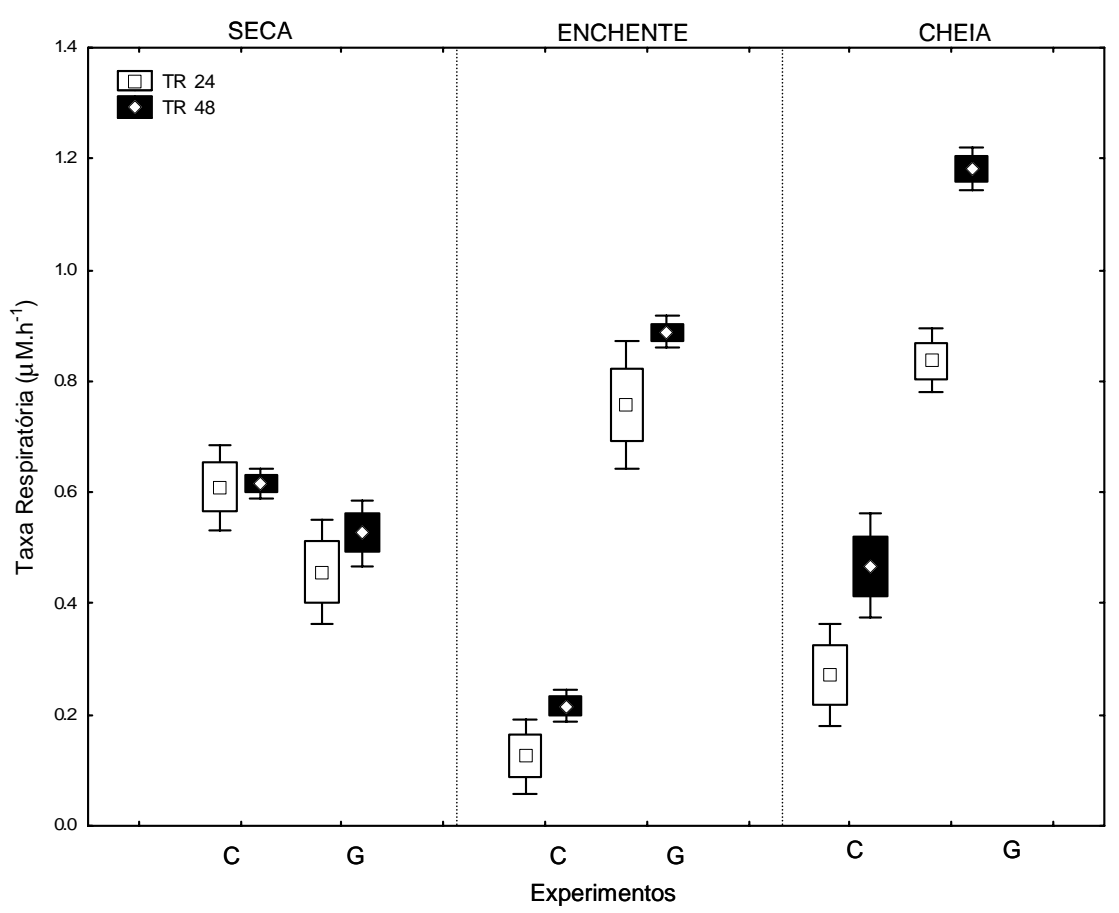

Figura 24 - Variação das taxas respiratórias no rio Comemoração, após 24 e 48 horas de incubação, nas amostras Controle (C) e enriquecidas com Sedimentos em Suspensão Grossos (G). Valores em $\mu \mathrm{M} \cdot \mathrm{h}^{-1}$

Resultados opostos foram observados nos períodos de enchente e cheia, quando a adição do concentrado de sedimentos grossos resultou em aumentos estatitiscamente significativos nas taxas respiratórias. Durante a enchente, após a adição de sedimentos grossos e incubação por 24 horas, as taxas respiratórias aumentaram de $0,13 \mu \mathrm{M} \cdot \mathrm{h}^{-1}$ a $0,76 \mu \mathrm{M} \cdot \mathrm{h}^{-1}\left(\mathrm{r}^{2}=0,94\right.$ e $\left.\mathrm{p}=0,03\right)$. Após 48 horas, este aumento foi de $0,22 \mu \mathrm{M} \cdot \mathrm{h}^{-1}$ a 0,89 $\mu \mathrm{M} \cdot \mathrm{h}^{-1}\left(\mathrm{r}^{2}=0,99\right.$ e $\left.\mathrm{p}=0,01\right)$. No período de cheia, após 24 horas de incubação, as taxas respiratórias aumentaram de $0,27 \mu \mathrm{M} \cdot \mathrm{h}^{-1}$ para 0,84 $\mu \mathrm{M} \cdot \mathrm{h}^{-1}\left(\mathrm{r}^{2}=0,95\right.$ e p =0,03) e, após 48 horas, $0,47 \mu \mathrm{M} \cdot \mathrm{h}^{-1}$ para $1,18 \mu \mathrm{M} \cdot \mathrm{h}^{-1}\left(\mathrm{r}^{2}=0,97\right.$ e $\left.\mathrm{p}=0,02\right)$. 


\section{Rio Urupá}

Neste rio, no período de seca, a adição de sedimentos em suspensão grossos acarretou em diminuição das taxas respiratórias, após 24 horas de incubação, e aumento após 48 horas, ambas variações estatisticamente não significativas (Figura 25). $\mathrm{Na}$ primeira, os valores observados passaram de $0,81 \mu \mathrm{M} \cdot \mathrm{h}^{-1}$ a $0,78 \mu \mathrm{M} \cdot \mathrm{h}^{-1}\left(\mathrm{r}^{2}=0,16\right.$ e $\mathrm{p}=$ $0,60)$ e, na segunda, de $0,65 \mu M \cdot h^{-1}$ a $0,74 \mu M \cdot h^{-1}\left(r^{2}=0,59\right.$ e $\left.p=0,23\right)$.

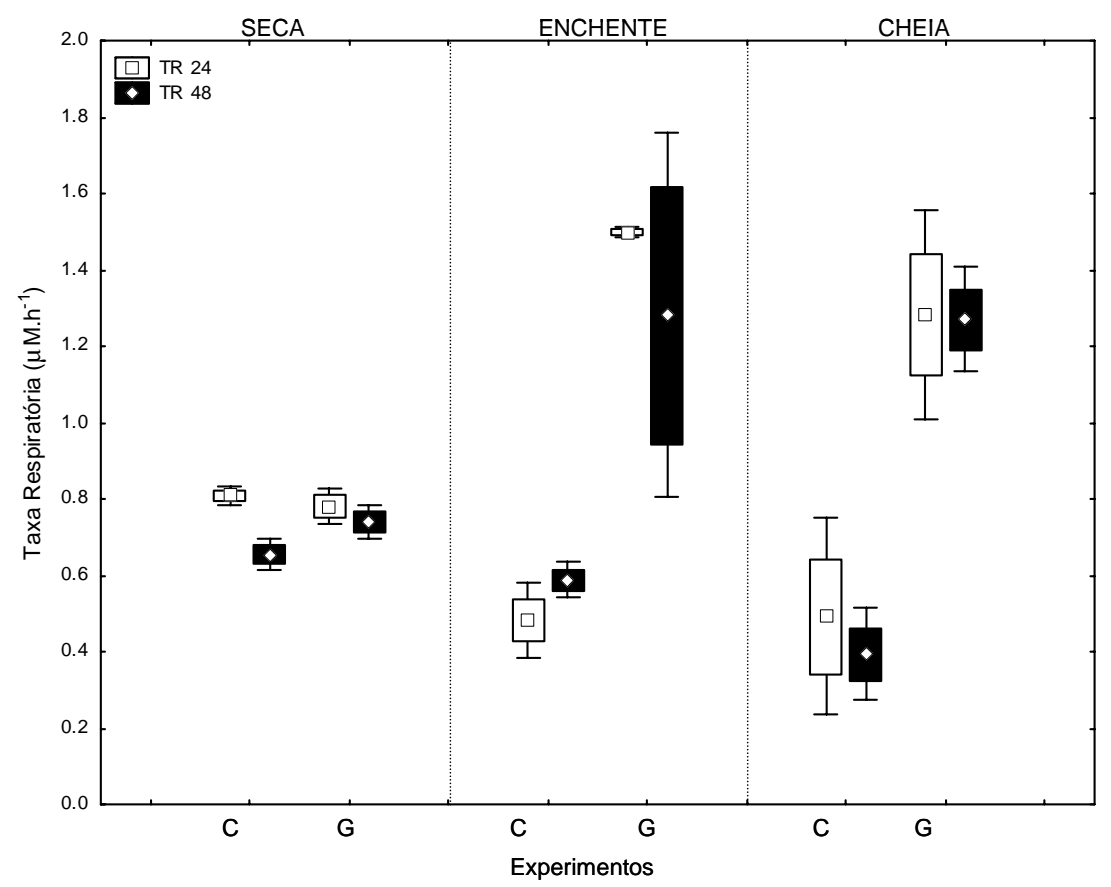

Figura 25 - Variação das taxas respiratórias no rio Urupá, após 24 e 48 horas de incubação, nas amostras Controle (C) e enriquecidas com Sedimentos em Suspensão Grossos (G). Valores em $\mu \mathrm{M} \cdot \mathrm{h}^{-1}$

No período de enchente, a influência da adição de sedimentos grossos nas taxas respiratórias passa a ser estatisticamente significativa, provocando um aumento nas mesmas de 0,48 $\mu \mathrm{M} \cdot \mathrm{h}^{-1}$ para $1,50 \mu \mathrm{M} \cdot \mathrm{h}^{-1}\left(\mathrm{r}^{2}=0,98\right.$ e $\left.\mathrm{p}=0,01\right)$, após 24 horas de 
incubação. Resultados similares foram observados após 48 horas de incubação, quando as taxas respiratórias aumentaram de $0,59 \mu \mathrm{M} \cdot \mathrm{h}^{-1}$ para $1,28 \mu \mathrm{M} \cdot \mathrm{h}^{-1}\left(\mathrm{r}^{2}=0,71 \mathrm{e} \mathrm{p}=0,16\right)$. Resultados similares foram observados no período de cheia, quando, após 24 horas de incubação, as taxas passaram de $0,49 \mu \mathrm{M} \cdot \mathrm{h}^{-1}$ a $1,28 \mu \mathrm{M} \cdot \mathrm{h}^{-1}\left(\mathrm{r}^{2}=0,76\right.$ e p $\left.=0,13\right)$ e, após 48 horas de incubação, de $0,39 \mu \mathrm{M} \cdot \mathrm{h}^{-1}$ a $1,27 \mu \mathrm{M} \cdot \mathrm{h}^{-1}\left(\mathrm{r}^{2}=0,94\right.$ e p = 0,03).

\section{Rio Ji-Paraná}

No rio Ji-Paraná, os padrões descritos acima se repetem, com variações não significativas nas taxas respiratórias, após a a adição de sedimentos em suspensão grossos. Neste caso, após as incubações de 24 horas, as taxas variaram de $0,39 \mu \mathrm{M} \cdot \mathrm{h}^{-1} \mathrm{a}$ $0,45 \mu \mathrm{M} \cdot \mathrm{h}^{-1}\left(\mathrm{r}^{2}=0,20\right.$ e p = 0,55), e de $0,44 \mu \mathrm{M} \cdot \mathrm{h}^{-1}$ a $0,49 \mu \mathrm{M} \cdot \mathrm{h}^{-1}\left(\mathrm{r}^{2}=0,70\right.$ e p = 0,16), após 48 horas de incubação (Figura 26).

No período de enchente, a adição de sedimentos em suspensão grossos provocou aumentos significativos nas taxas respiratórias, que variaram de $0,40 \mu \mathrm{M} \cdot \mathrm{h}^{-1}$ no controle a $0,83 \mu \mathrm{M} \cdot \mathrm{h}^{-1}$ nas garrafas incubadas por 24 horas $\left(\mathrm{r}^{2}=0,95\right.$ e $\left.\mathrm{p}=0,03\right)$, e de $0,41 \mu \mathrm{M} \cdot \mathrm{h}^{-}$ ${ }^{1}$ a $0,81 \mu \mathrm{M} \cdot \mathrm{h}^{-1}$, nas garrafas incubadas por 48 horas $\left(\mathrm{r}^{2}=0,88\right.$ e $\left.\mathrm{p}=0,06\right)$. No período de cheia, estes aumentos foram ainda maiores, com variações de 0,15 $\mu \mathrm{M} . \mathrm{h}-1$ a $0,89 \mu \mathrm{M} \cdot \mathrm{h}^{-1}$ $\left(r^{2}=0,97\right.$ e $\left.\mathrm{p}=0,02\right)$ após incubação por 24 horas, e de $0,25 \mu \mathrm{M} \cdot \mathrm{h}^{-1}$ a $1,02 \mu \mathrm{M} \cdot \mathrm{h}^{-1}$ após 48 horas $\left(\mathrm{r}^{2}=0,96\right.$ e $\left.\mathrm{p}=0,02\right)$. 


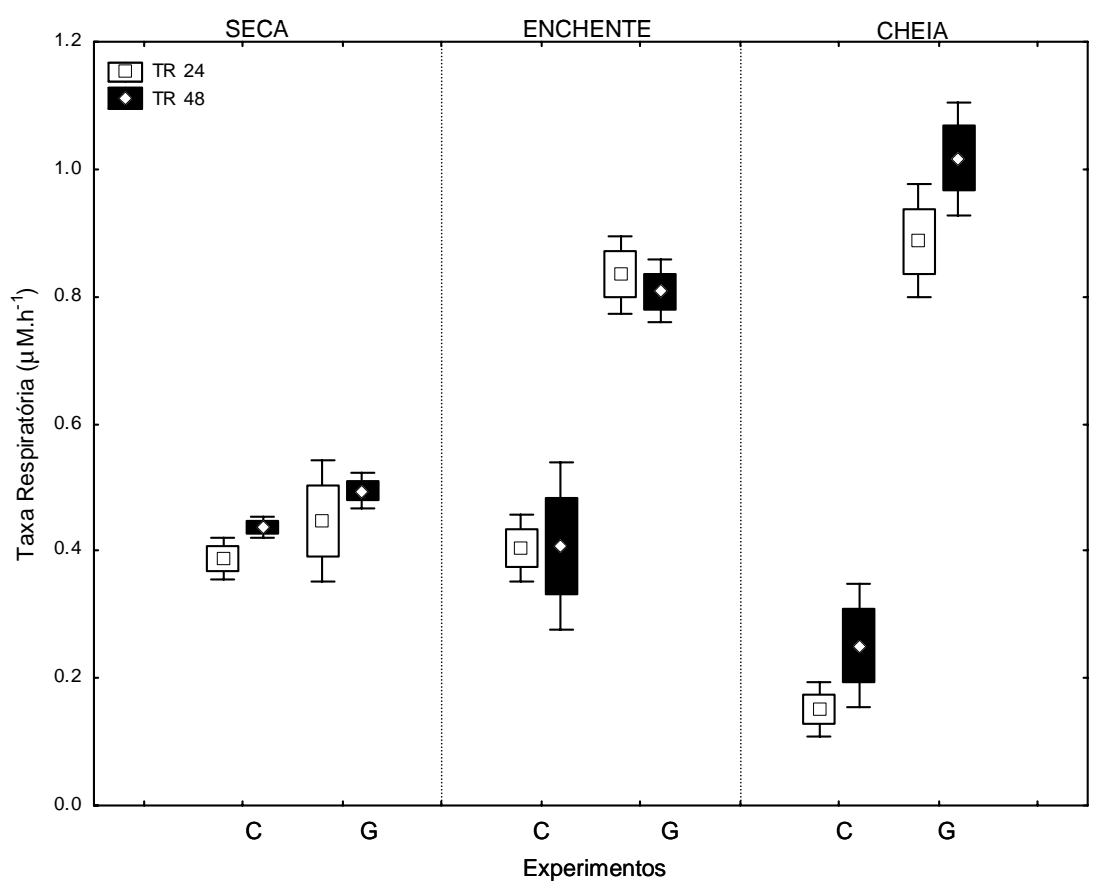

Figura 26 - Variação das taxas respiratórias no rio Ji-Paraná, após 24 e 48 horas de incubação, nas amostras Controle (C) e enriquecidas com Sedimentos em Suspensão Grossos (G). Valores em $\mu \mathrm{M} \cdot \mathrm{h}^{-1}$

\section{Setor da pastagem do Igarapé Boa Vista}

No trecho da pastagem do igarapé Boa Vista, apesar da adição de sedimentos em suspensão grossos resultar em incrementos mais discretos das taxas respiratórias no período de enchente, estatisticamente, os resultados não são distintos daqueles obtidos nos outros rios de ordem superior (Figura 27). No período de seca, as taxas variaram de $0,12 \mu \mathrm{M} . \mathrm{h}^{-1}$ no controle para $0,15 \mu \mathrm{M} \cdot \mathrm{h}^{-1}$ nas garrafas incubadas por 24 horas $\left(\mathrm{r}^{2}=0,13\right.$ e $\mathrm{p}=0,64$ ) e de $0,34 \mu \mathrm{M} \cdot \mathrm{h}^{-1}$ no controle para $0,42 \mu \mathrm{M} \cdot \mathrm{h}^{-1}$ nas garrafas incubadas por 48 horas $\left(\mathrm{r}^{2}=0,60\right.$ e $\left.\mathrm{p}=0,23\right)$.

Nos períodos de enchente e cheia, a adição de sedimentos provocou aumentos estatisticamente significativos nas taxas respiratórias. No primeiro, após 24 horas de 
incubação, as taxas aumentaram de 0,32 $\mu \mathrm{M} \cdot \mathrm{h}^{-1}$ para $0,61 \mu \mathrm{M} \cdot \mathrm{h}^{-1}\left(\mathrm{r}^{2}=0,91\right.$ e p = 0,05) e, após 48 horas, de $0,30 \mu \mathrm{M} \cdot \mathrm{h}^{-1}$ para $0,56 \mu \mathrm{M} \cdot \mathrm{h}^{-1}\left(\mathrm{r}^{2}=0,93\right.$ e $\left.\mathrm{p}=0,04\right)$. No segundo, após adição de sedimentos grossos e incubação por 24 horas, houve um aumento de 0,20 $\mu \mathrm{M} . \mathrm{h}^{-1}$ no controle para $1,59 \mu \mathrm{M} . \mathrm{h}^{-1}$ nas garrafas incubadas $\left(\mathrm{r}^{2}=0,98\right.$ e $\left.\mathrm{p}=0,01\right)$ e, após incubações por 48 horas, de 0,26 $\mu \mathrm{M} \cdot \mathrm{h}^{-1}$ para $1,44 \mu \mathrm{M} \cdot \mathrm{h}^{-1}\left(\mathrm{r}^{2}=0,95\right.$ e $\left.\mathrm{p}=0,03\right)$.

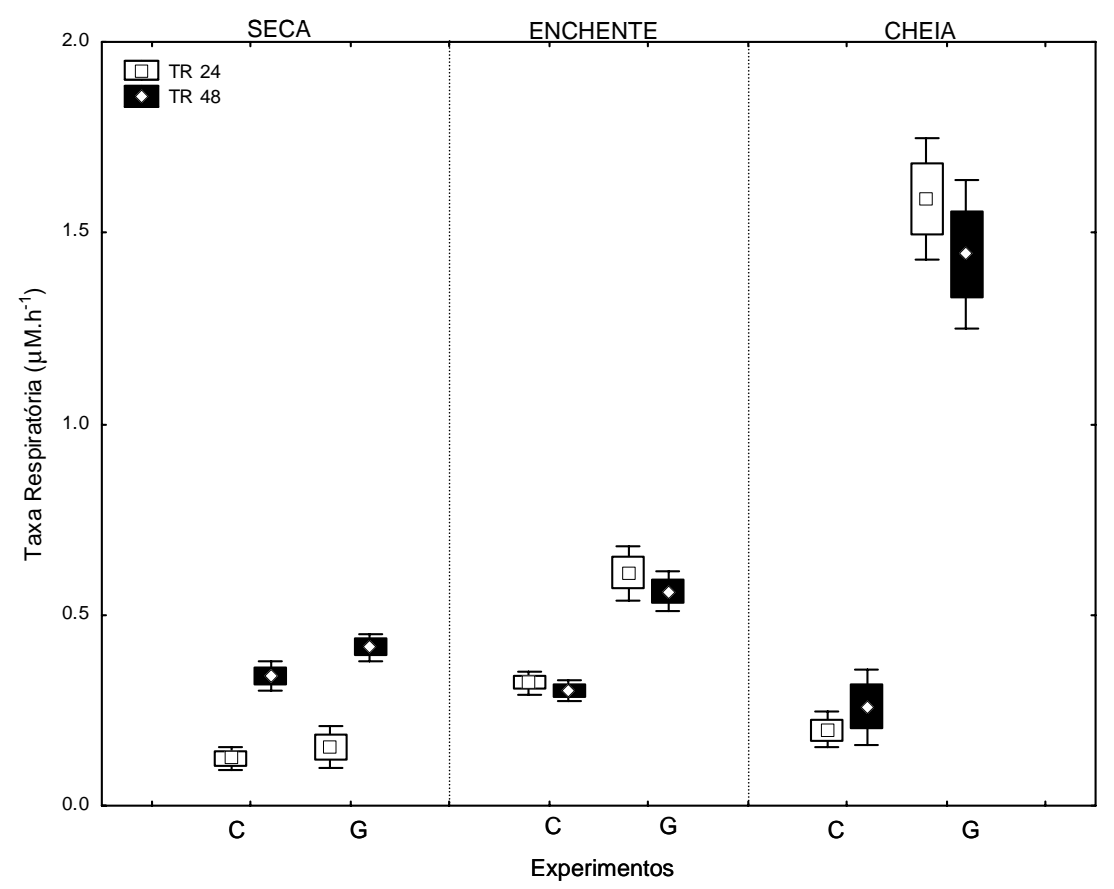

Figura 27 - Variação das taxas respiratórias no setor da pastagem do Igarapé Boa Vista, após 24 e 48 horas de incubação, nas amostras Controle (C) e enriquecidas com Sedimentos em Suspensão Grossos (G). Valores em $\mu M \cdot h^{-1}$

\section{Setor da floresta do Igarapé Boa Vista}

No setor na floresta do Igarapé Boa Vista observaram-se os resultados mais díspares da influência da adição de sedimentos em suspensão grossos nas taxas respiratórias (Figura 28). Neste local, o acesso impossibilitou a obtenção de amostras no período de cheia. Nos experimentos referentes às outras épocas do ano, apenas no 
período de enchente e, após 24 horas de incubação, houve incremento estatisticamente significativo das taxas respiratórias, que variaram de $0,40 \mu \mathrm{M} \cdot \mathrm{h}^{-1}$ no controle para 0,61 $\mu \mathrm{M} \cdot \mathrm{h}^{-1}$ nas garrafas enriquecidas $\left(\mathrm{r}^{2}=0,90\right.$ e $\left.\mathrm{p}=0,05\right)$. Neste mesmo período, após 48 horas de incubação, as taxas variaram de $0,53 \mu \mathrm{M} \cdot \mathrm{h}^{-1}$ a $0,58 \mu \mathrm{M} \cdot \mathrm{h}^{-1}\left(\mathrm{r}^{2}=0,01\right.$ e $\mathrm{p}=$ $0,90)$.

Assim como nos outros rios estudados, neste caso, no período de seca a adição do concentrado de sedimentos em suspensão grossos não provocou alterações estatisticamente significativas nas taxas respiratórias, pois as mesmas variaram de 0,61 $\mu \mathrm{M} \cdot \mathrm{h}^{-1}$ no controle a 0,56 $\mu \mathrm{M} \cdot \mathrm{h}^{-1}$, após incubação por 24 horas $\left(\mathrm{r}^{2}=0,07\right.$ e $\left.\mathrm{p}=0,74\right)$ e de $0,45 \mu \mathrm{M} \cdot \mathrm{h}^{-1}$ a $0,44 \mu \mathrm{M} \cdot \mathrm{h}^{-1}\left(\mathrm{r}^{2}=0,03\right.$ e $\left.\mathrm{p}=0,83\right)$, após 48 horas de incubação.

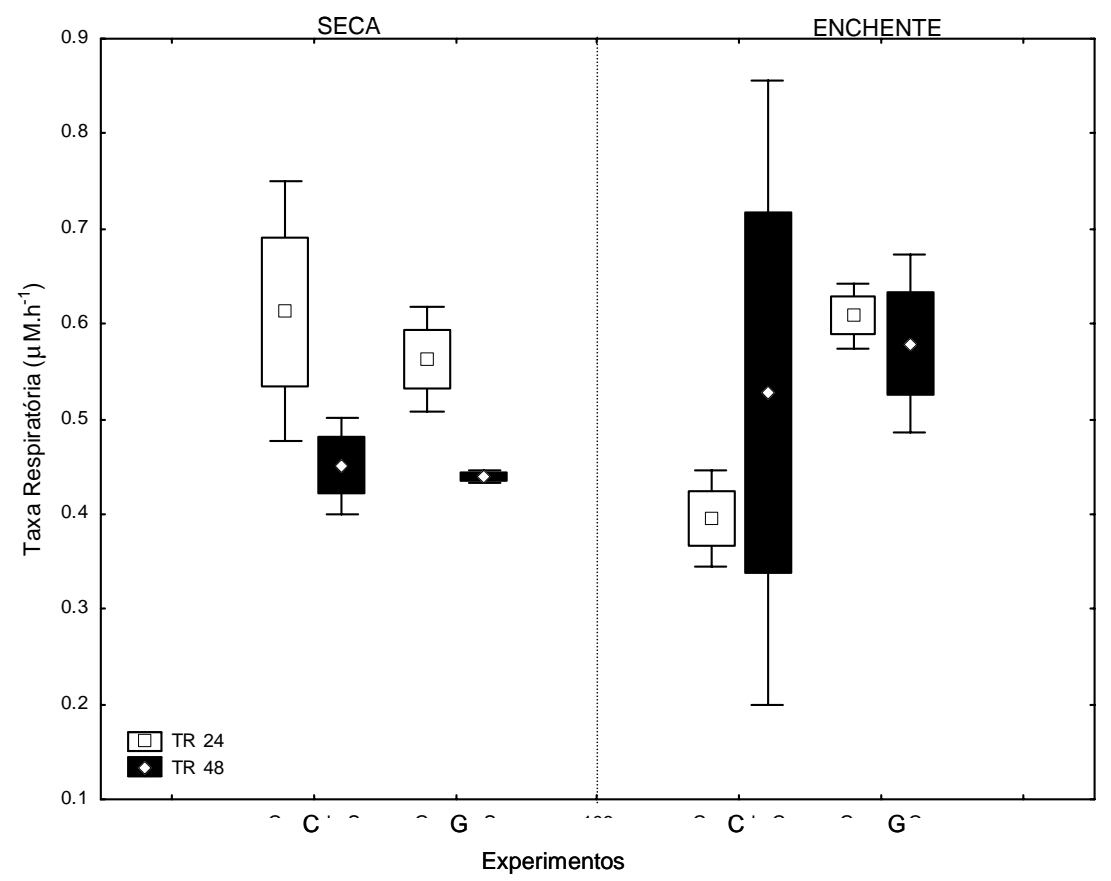

Figura 28 - Variação das taxas respiratórias no setor de floresta do Igarapé Boa Vista, após 24 e 48 horas de incubação, nas amostras Controle (C) e enriquecidas

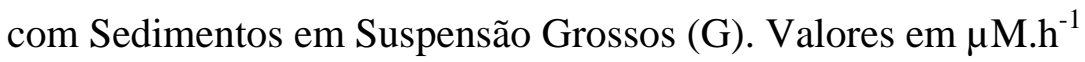




\section{CONCLUSÕES}

- O tipo de solo bem como a cobertura vegetal da bacia de drenagem influencia a dinâmica do ecossistema aquático, devido a disponibilização de carbono e nutrientes essenciais para o ecossistema aquático como substrato para a respiração do material adsorvido aos sedimentos, que podem ser disponibilizados ao serem dessorvidos nas amostras incubadas.

- As alterações nas taxas respiratórias (consumo de oxigênio) sugerem que não somente as concentrações dos sedimentos em suspensão foram fatores determinantes no metabolismo aquático destes rios, mas também à quantidade e qualidade do carbono orgânico dissolvido são fatores que altera toda a dinâmica do ecossistema fluvial, para esta região. 


\section{REFERÊNCIAS BIBLIOGRÁFICAS}

AITKENHEAD, J.A.; HOPE, D.; BILLET, M.F. The relationship between dissolved organic carbon in stream water and soil organic carbon pools at different spatial scales. Hydrologic Processes, v.13, p.1289-1302, 1999.

AITKENHEAD-PETERSON, J.A.; McDOWELL, W.H.; NEFF, J.C. Sources, production, and regulation of alloctonous dissolved organic matter inputs to surface waters. In: FINDLAY, S.E.G.; SINSABAUGH, R.L. (Ed). Aquatic Ecosystems - Interactivity of Dissolved Organic Matter. United States of America: Academic Press, 2003. cap. 2, p.25-70.

ATLAS GEOAMBIENTAL DE RONDÔNIA. Porto Velho: SEDAM, p.v.2. 2002.

AUFDENKAMPE, A.K.; HEDGES, J.I.; RICHEY, J.E. Sorptive fractionation of dissolved organic nitrogen and amino acids onto fine sediments within the Amazon Basin. Limnology and Oceanography, v. 46, n.8, p.1921-1935, 2002.

AUFDENKAMPE, A.K.; HEDGES, J.I.; RICHEY, J.E.; KRUSCHE, A.V.; LLERENA, C.A. Sorptive fractionation of dissolved organic nitrogen and amino acids onto fine sediments within the Amazon Basin. Limnology and Oceanography, v.46, n.8, p.1921-1935, 2001. 
BAKER, J.P.; SCHOFIELD, C.L. Aluminium toxicity to fish in acidic waters. Water Air Soil Pollution, v.19, p.289-309, 1982.

BALLESTER, M.V.R.; VICTORIA, D.D.; KRUSCHE, A.V.; COBURN, R.; VICTORIA, R.L.; RICHEY, J.E.; LOGSDON, M.G.; MAYORGA, E.; MATRICARDI, E. A remote sensing/GIS-based physical template to understand the biogeochemistry of the Ji-Paraná river basin (Western Amazonia). Remote Sensing of Environment, v.87, n.4, p.429-445, 2003.

BAAS-BECKING, L.G.M.; MOORE, D. The relation between iron and organic matter in sediments J. Sediment. Petrol., v.29, p.454-458, 1959.

BENNER, R. Ultrafiltration for the concentration of bacteria, viruses, and dissolved organic matter. Geophysical Monographs, v.63, p.181-185, 1991.

BUFFLE, J. Natural organic matter and metal-organic interactions in aquatic systems. In Metal Ions in Biological Systems, Vol. 18, ed. H. Sigel. Marcel Dekker, New York, pp. 166-221, 1984.

CLETO FILHO, S.E.N. Urbanização poluição e biodiversidade na Amazônia. Revista Ciência Hoje, v.33, n.193, p.72-75. 2003.

DAVIDSON, E.A.; NEILL, C.; KRUSCHE, A.V.; BALLESTER, M.V.R.; MARKEWITZ, D.; FIGUEIREDO, R.O. Loss of nutrient from terrestrial ecosystems 
to streams and the atmosphere following land use change in Amazonia. In: DEFRIES, R.S. (Ed), American Geophysical Union, Hardcover, p. 147-158, 2004.

DEPETRIS, P.J.; PAOLINI, J.E. Biogeochemical aspects of South American Rivers: The Paraná and the Orincoc. In: DEGENS, E.T.; KEMPE, S.; RICHEY, J.E. (Ed). Biogeochemistry of Major World Rivers. New York: John Wiley \& Sons, 1991. cap. 5, p. 105-125.

DEVOL, A.H.; FORSBERG, B.R.; RICHEY, J.E.; PIMENTEL, T.P. Seasonal variation in chemical distributions in the Amazon (Solimões) River: a multiyear time series. Global Biogeochemistry Cycles v.9, p.307-328, 1995.

EMBRAPA - Empresa Brasileira de Pesquisa Agropecuária. Mapa de levantamento de reconhecimento de média intensidade dos solos do Estado de Rondônia. Mapas 73, 74, 75 e 76. CEPA, 1983.

EMBRAPA - Empresa Brasileira de Pesquisa Agropecuária. Sistema Brasileiro de Classificação de Solos. Brasília: Embrapa Produção de Informação, 412p., 1999.

ESHLEMAN, K.N.; HEMOND, H.F. The role of organic acids in the acid-base status of surface waters at Bickford Watershed, Massachusetts. Water Resource Research, v.21, p.1503-1510, 1985.

FORSBERG, B.R.; DEVOL, A.H.; RICHEY, J.E.; MARTINELLI, L.A.; SANTOS, H. Factors controlling nutrient concentration in Amazon floodplain lakes. Limnology and Oceanography, v.33, p.41-56, 1988. 
GIBBS, J.R. The geochemistry of the Amazon River system: Part I. The factors that control the salinity and the composition and concentration of suspended solids. Geological Society of America Bulletin, v.78, p.1202-1232, 1967.

HANADA, L.C. Mudanças no uso e cobertura do solo na fronteira agrícola da Amazônia Ocidental, Bacia do Ji-Paraná - Rondônia. Piracicaba, 2004. 74p. Dissertação (Mestrado) - Escola Superior de Agricultura “Luiz de Queiroz”, Universidade de São Paulo.

HAUER, F. R.; LAMBERTI, G.A. Methods in Stream Ecology. Academic Press, New York, NY, Academic Press. 1996. 674pp.

HUNSAKER, C.T.; LEVINE, D.A. Hierarchical Approaches to the Study of Water Quality in Rivers. BioScience, v.45, p.193-203, 1995.

ITTEKKOT, V.; LAANE, R.W.P.M. Fate of riverine particulate organic matter. In: DEGENS, E.T.; KEMPE, S.; RICHEY, J.E. (Ed). Biogeochemistry of Major World Rivers. New York: John Wiley, 1991. cap. 10, p. 233-243.

JENNE, E.A. Sorption phenomenon in organics of bottom sediments. Progress in Water Technology, v.7, p.131-136, 1975.

KAUFFMAN, J.B.; CUMMINGS, D.L.; WARD, D.E. Fire in the Brazilian Amazon: 2. Biomass, nutrient pools and losses in cattle pastures. Oecologia, v.113, p. 415427, 1998. 
KEIL, R.G.; TSAMAKIS, E.; FUH, C.B.; GIDDINGS, J.C.; HEDGES, J.I. Mineralogical and textural controls on the organic composition of coastal marinesediments - Hydrodynamic separation using Splitt-Fractionation. Geochimica et Cosmochimica Acta, v.58, n.2, p.879-893, 1994.

KEIL, R.G.; MAYER, L.M.; QUAY, P.D.; RICHEY, J.E.; HEDGES, J.I. Loss of organic matter from riverine particles in deltas. Geochimica et Cosmochimica Acta, v.61, n.7, p.1507-1511, 1997.

KEREKES, J.; BEAUCHAMP, S.; TORDON, R.; TREMBLAY, C.; POLLOCK, T. Organic versus anthropogenic acidity in tributaries of the Kejimkujik watersheds in western Nova Scotia. Water Air Soil Pollution, v.31, p.165-173, 1986.

LEITE, N.K. A Biogeoquímica do Rio Ji-Paraná, Rondônia. Piracicaba, 2004. 44p. Dissertação (Mestrado) - Escola Superior de Agricultura "Luiz de Queiroz", Universidade de São Paulo.

LINKENS, G.E.; BORMAN, F.H.; JOHNSON, N.M.; FISHER, D.W.; PIERCE, R.S. Effects of forest cutting and hubicide treatment on nutrient budget in the Hubbard Brook watershed-ecosystem. Ecological Monographs, v.40, p.23-47, 1970.

LUDWIG, W. Continental erosion and river transport of organic carbon to the world's oceans. Strasbourg, 1996. 211p. Thesis (Doctor), Universite Louis Pasteur.

MARGALEF, R. Limnology: Reconsidering ways and goals. Memorie Dell' istituto Italiano Di Idrobiologia Dott. Marco de Marchi, v. 47, p.57-76, 1990. 
MEADE, R.H.; DUNNE, T.; RICHEY, J.E.; SANTOS, U.M.; SALATI, E. Storage and remobilization of sediment in the lower Amazon River of Brazil. Science, v.228, p.488-490, 1985.

MELACK, J.M. Transport and transformations of P in fluvial and lacustrine ecosystems. In: Tiessen, H. (Ed.). Phosphorus in the Global Environment. New York: J. Wiley, 1995. p.245-254 (SCOPE 54).

MEYER, J.L.; McDOWELL, W.H.; BOTT, T.L.; ELWOOD, J.W.; ISHIZAKI, C.; MELACK, J.M.; PECKARSKY, B.L.; PETERSON, B.J.; RUBLEE, P.A. Elemental Dynamics in Streams. Journal of the North American Benthological Society, v.7, n.4, p.410-432, 1988.

McCLAIN, M.E.; ELSENBEER, H. Terrestrial inputs to Amazon streams and internal biogeochemical processing. In: McCLAIN, M.E.; VICTORIA, R.L.; RICHEY, J.E. (Ed.). The Biogeochemistry of the Amazon Basin. Oxford, 2001. 365p.

McClAIN, M. E.; RICHEY, J. E.; BRANDES, J. A.; PIMENTEL, T. P. Dissolved organic matter and terrestrial-lotic linkages in the central Amazon basin of Brazil. Global Biogeochemical Cycles, v.11, p.295-311, 1997.

MINISTÉRIO DO MEIO AMBIENTE. Desmatamento é o Segundo maior da história da Amazônia. [on line]. http://www.amazonia.org.br/guia/detalhes, (dez, 2004).

MORISAWA, M. Streams: Their dynamics and morphology. New York: McGraw-Hill, 1968. 175pp. 
NEILL, C.; DEEGAN, L. A.; THOMAS, S. M.; CERRI, C. C. Deforestation for pasture alters nitrogen and phosphorus in small Amazonian Streams. Ecological Applications, v.11, p.1817-1928, 2001.

NEU, V. Influência da cobertura vegetal na ciclagem de nutrientes via solução do solo na região de Manaus AM. Piracicaba, 2005. 93p. Dissertação (Mestrado) Escola Superior de Agricultura “Luiz de Queiroz”, Universidade de São Paulo.

OLIVER, B.G.; THURMAN, E.M.; MALCOLM, R.L. The contribution of humic substances to the acidity of coloured natural waters. Geochimica et Cosmochimica Acta, v.47, p.2031-2035, 1983.

PERDUE, E.M.; GJESSING, E.T. Organic acids in aquatic systems. Berlin, Ge: PERDUE, E.M.; GJESSING, E.T. (Ed.). 1989. 345p.

REUTER, J.; PERDUE, E.M. Importance of heavy metal-organic matter interactions in natural waters. Geochimica et Cosmochimica Acta, v.41, p.325-334, 1977.

RICHEY, J.E.; VICTORIA, R.L. C, N and P export dynamics in the Amazon River. In: Wollast et al. (Ed.). Springer-Verlag, Berlin: Interactions of C, N, P, and S biogeochemical cycles and global change. p.123-140, 1993.

SCANDOLARA, J.E.; RIZZOTO, G.J.; BAHIA, R.B.C.; QUADROS, M.L.E.S.;SILVA, C.R.; AMORIN,. J.L. Geologia do Estado de Rondônia. Porto velho: Companhia de Pesquisa de Recursos Minerais, 1998. 66p. 
SCNITZER, M.; KHAN, S.U. Humic substances in the environment". New York: Marcel Dekker. 1972. v.1.

SHARPLEY, N.A.; HEDLEY, M.J.; SIBBESEN, E.; HILLBRICHT-ILKOWSKA, A.; HOUSE, W.A.; RYSKOWSKI, I. Phosphorus transfers from terrestrial to aquatic systems. In: Tiessen, H. (Ed.). Phosphorus in the global environment. New York: John Wiley, 1995. p.171-200, (SCOPE 54).

STALLARD, R.F.; EDMOND, J.M. Geochemistry of the Amazon .2. The Influence of Geology and Weathering Environment on the Dissolved-Load. Journal of Geophysical Research-Oceans and Atmospheres, v.88, p. 9671-9688, 1983.

STALLARD, R.F.; EDMOND, J.M. Geochemistry of the Amazon .3. Weathering chemistry and limits to dissolved inputs. Journal of Geophysical Research-Oceans, v.92, p. 8293-8302, 1987.

STATSOFT, Inc. (2004). STATISTICA (data analysis software system), version 6 . www.statsoft.com

SWANK, W.T.; GROSSLEY, D.A. (Ed.). Forest Hydrology and Ecology at Coweeta. New York: Springer-Verlag, 1988. v.1.

THOMAZ, S.M.; PEREIRA, G.; PAGIORO, T.A. Microbial respiration and chemical composition of different sediment fractions in waterbodies of the upper Paraná river floodplain, Brazil. Revista Brasileira de Biologia, v.61, n.2, p.277-286, 2001. 
THOMAS, S.M.; NEILL, C.; DEEGAN, L.A.; KRUSCHE, A.V.; BALLESTER, M.V.R.; VICTORIA, R.L. Influences of land use and stream size on particulate and dissolved materials in a small Amazonian stream network. Biogeochemistry, v.68, n.2, p.135-151, 2004.

THURMAN, E.N. Nijhoff/Junk, Dordrecht: Organic geochemistry of natural waters.1985. v.1.

VICTORIA, R.L. Entendendo a hidrologia de superfície da Amazônia: Uma visão biogeoquímica. In: Conferência Científica do LBA, Brasília: LBA, 2004.

VITOUSEK, P.M.; GOSZ, J.R.; GRIER, C.C.; MELILLO, J.; REINERS, W.A.; TOOD, R.L. Nitrate losses from disturbed ecosystems. Science, n.204, p.469-474, 1979.

WETZEL, R.G. Death, detritus, and energy-flow in aquatic ecosystems. Freshwater Biology, v.33, n.1, p.83-89, 1995.

WETZEL, R.G. Gradient-dominant ecosystems: sources and regulatory functions of dissolved matter in freshwater ecosystems. Hydrobologia, v.229, p.181-198, 1992.

WETZEL, R. G.; LIKENS, G. E. Limnological Analyses. New York: Springer-Verlag, 1991. v.1. 